\title{
El crédito portugués en la Monarquía Hispánica de Felipe IV: los asientos de la familia Núñez-Mercado (1640-1652)
}

\author{
Álvaro Sánchez Durán ${ }^{2}$
}

Recibido: 19 de diciembre de 2016 / Aceptado: 13 de junio de 2017

Resumen. El presente estudio tiene por objeto la reconstrucción de la trayectoria financiera de una familia de hombres de negocios judeoconversos portugueses durante el reinado de Felipe IV: los NúñezMercado. Se examinará la influencia de la estrecha relación entre uno de sus patriarcas, Henrique Núñez, y un ministro real, el conde de Peñaranda de Bracamonte, en la consecución del acceso a las finanzas de la Monarquía Hispánica. A su vez, se analizarán algunos de sus contratos para la provisión del Ejército de Extremadura, así como los distintos mecanismos mediante los cuales los Núñez-Mercado financiaban sus asientos. También será abordada la nueva relación contractual entre la Corona y esta casa de negocios portuguesa tras la bancarrota real decretada en 1647, plasmada en la vinculación de sus nuevos asientos con el arrendamiento de rentas reales. Por último, se reseñará brevemente la desaparición de esta firma familiar como consecuencia del procesamiento y detención de Manuel Núñez Mercado por la Inquisición en 1652.

Palabras clave: hombres de negocios; cristianos nuevos portugueses; Núñez-Mercado; asientos; Monarquía Hispánica.

\section{[en] Portuguese Credit in Philip IV's Spanish Monarchy: the Asientos of the Núñez-Mercado Family (1640-1652)}

\begin{abstract}
This study reconstructs the financial career of the Núñez-Mercado family of Portuguese New Christian businessmen during the reign of Philip IV. It sheds light on the influence it achieved thanks to the close relationship between one of the family's heads, Henrique Núñez, and a royal minister, the Count of Peñaranda de Bracamonte, which opened the way to its participation in the finances of the Spanish Monarchy. After examining different contracts for the provision of the Army of Extremadura and the mechanisms by which the Núñez-Mercado financed their asiento contracts, it assesses the new contractual relationship developed between the Spanish Crown and this Portuguese banking house following the royal bankruptcy of 1647 , which led to its linking new asientos with tax-farming contracts. It concludes with a brief description of the extinction of the family firm following the arrest and prosecution of Manuel Núñez Mercado by the Inquisition in 1652 .
\end{abstract}

Keywords: Businessmen; Portuguese New Christians; Núñez-Mercado; Asientos; Spanish Monarchy.

$1 \quad$ Este artículo se inserta en el Proyecto de Investigación Nuevas perspectivas de historia social en la ciudad de Madrid y sus áreas de influencia en la época moderna (HAR2014-53298-C2-2-P), financiado por el Ministerio de Economía y Competitividad. La realización del mismo ha sido posible gracias a la obtención de una ayuda del Programa de Formación de Profesorado Universitario (FPU 2013) del Ministerio de Educación, Cultura y Deporte.

2 Universidad Autónoma de Madrid (España) alvaro.sanchezd@uam.es 
Sumario. 1. El acceso a las finanzas reales: Henrique Núñez, un homo novus portugués. 2. Asientos de provisión del Ejército de Extremadura (1641-1647). 3. El caudal y crédito de los asientos: comercio interregional, exportación de lanas y letras. 4. Quiebra y reconstrucción del crédito: la bancarrota de 1647 y sus consecuencias. 5. La Inquisición y el fin de una casa de negocios de la nación portuguesa. 6. Conclusiones.

Cómo citar: Sánchez Durán, A. (2017) El crédito portugués en la Monarquía Hispánica de Felipe IV: los asientos de la familia Núñez-Mercado (1640-1652), en Cuadernos de Historia Moderna 42.1, 5786.

A principios de 1649 Baltasar Rodríguez Núñez, nuevo tesorero general de la renta de la seda del Reino de Granada, refería en una carta a su hermano y socio Juan Rodríguez Núñez, asentista de su Majestad, los beneficios futuros que esperaba obtener para la firma familiar a partir de la recién contratada renta:

En quanto a lo gustoso que quedo le prometo lo puede VMd quedar también por la parte que le tocará que es la coza más onrrada del mundo y la mejor jente dél. Y le prometo, se Dios es servido, que a de ser la casa de más crédito d'España ésta dentro de un año ${ }^{3}$.

Este breve fragmento resulta representativo de las expectativas atesoradas por múltiples casas de negocios de la "nación portuguesa" implicadas en actividades financieras con la Monarquía Hispánica durante el reinado de Felipe IV (1621-1665). En concreto, de un grupo muy nutrido de familias judeoconversas de origen socioeconómico modesto y procedentes en su mayoría de regiones del interior de Portugal -Beira, Trás-os-Montes, Alentejo--, las cuales se asentaron en la vecina Corona de Castilla desde fines del siglo XVI y a lo largo de la primera mitad del siglo XVII para dedicarse fundamentalmente a actividades comerciales. El establecimiento en Madrid de una serie de acaudalados e influyentes clanes financieros lisboetas, invitados desde 1626 por Felipe IV y su valido el conde-duque de Olivares a invertir su capital en asientos de provisiones generales para Flandes, Italia o Alemania, supondría un revulsivo para el crédito de esas parentelas de segunda fila 4 .

De hecho, a partir de la década de 1630 los anteriores irían orientando progresivamente su capital hacia el arrendamiento de rentas locales y reales ${ }^{5}$. En gran medida como consecuencia de la desarticulación de las redes de contrabando entre la península ibérica, Francia y las Provincias Unidas ${ }^{6}$. De modo que el abandono del

3 Carta de Baltasar Rodríguez Núñez (Granada) a Juan Rodríguez Núñez (Madrid), 5 de enero de 1649, Archivo Histórico Nacional (AHN), Inquisición, leg. 3951.

4 Boyajian, J. C.: Portuguese Bankers at the Court of Spain, 1626-1650, New Brunswick, Rutgers University Press, 1983, pp. 17-41. Con respecto a los banqueros genoveses, Domínguez OrTiz, A.: Política y hacienda de Felipe IV, Madrid, Editorial de Derecho Financiero, 1960, pp. 109-126. Álvarez Nogal, C.: Los banqueros de Felipe IV y los metales preciosos americanos (1621-1665), Madrid, Banco de España, 1997, pp. 51-88.

5 López Belinchón, B. J.: Honra, libertad y hacienda (Hombres de negocios y judíos sefardies), Alcalá de Henares, Universidad de Alcalá, 2001, pp. 141-151. CARrasco VÁzQUEZ, J. A.: La minoría judeoconversa en la época del conde duque de Olivares. Auge y ocaso de Juan Núñez Saravia (1585-1639), tesis doctoral inédita, Universidad de Alcalá, 2004.

6 López Belinchón, B. J.: “«Sacar la sustancia al Reino». Comercio, contrabando y conversos portugueses, 16211640”, Hispania. Revista Española de Historia, vol. LXI/3, 209 (2001), pp. 1017-1050. Alloza Aparicio, A.: "La Junta del Almirantazgo y la lucha contra el contrabando, 1625-1643", Espacio, Tiempo y Forma. Serie IV. Historia Moderna, 16 (2003), pp. 217-254. 
comercio por la gestión de rentas sería el primer paso hacia una mayor implicación en las finanzas de la Monarquía. Las urgentes necesidades de numerario de la Corona para afrontar los ingentes gastos de sus frentes bélicos europeos -también peninsulares desde 1640- les proporcionarían una vía de acceso al privilegiado círculo de banqueros conformado por los "asentistas de su Majestad". No obstante, el menor estatus socioeconómico de los referidos negociantes de segunda fila conllevaría una posición subalterna con respecto a las grandes casas lisboetas que encabezaron las finanzas reales al menos hasta $1647^{7}$. A pesar de su menor participación en las redes financieras atlánticas, no se puede menospreciar el destacado papel que desempeñarían en la articulación y explotación del crédito interior en territorio peninsular. Considerados en su conjunto, los hombres de negocios de la nación portuguesa mantendrían una enorme influencia en las finanzas de la Monarquía Hispánica hasta la década de 1650, que marcaría el comienzo de un periodo de grandes causas inquisitoriales contra buena parte de los mismos en virtud de su presunta adhesión a prácticas de culto criptojudías. Y es que sólo un número reducido de linajes podrían salvar el obstáculo constituido por el "pecado social" dimanado de su ascendencia judeoconversa ${ }^{8}$.

Los hermanos Baltasar Rodríguez Núñez (c. 1610-1650), Juan Rodríguez Núñez (c. 1616-1649) y Manuel Núñez Mercado (c. 1627-1656) constituyeron parte de uno de los referidos linajes portugueses de procedencia más humilde: los Núñez-Merca$\mathrm{do}^{9}$. Originarios de la villa de Penamacor, en la Beira, sus distintas ramas se fueron instalando en la Corona de Castilla a lo largo de las primeras décadas del siglo XVII. Concretamente en diferentes localizaciones de la fronteriza provincia de Extremadura, desde donde se dedicarían al comercio al por mayor entre sus principales ferias regionales ${ }^{10}$. Una de las primeras incursiones de esta familia en negocios con la Real Hacienda sería protagonizada por Francisco Rodríguez Penamacor (c. 1595-1650), arrendador del impuesto del papel desde 1637 hasta al menos 1644, así como arrendador de los derechos del azúcar y conservas entre 1638 y $1648^{11}$. Pero el peso más

7 Los asentistas procedentes de Lisboa con mayor negociación en el periodo 1626-1647 fueron los siguientes: Manuel de Paz, Fernando Tinoco, Jorge de Paz Silveira, Duarte Fernández de Acosta, Simón Suárez Dorta, Salvador Báez Martínez, Duarte Brandón Suárez y Duarte Díaz de Olivares. Boyajian, op. cit. (nota 4), pp. 26-33 y 133-137.

8 Dedieu, J. P.: “¿Pecado original o pecado social? Reflexiones en torno a la constitución y definición del grupo judeo-converso en Castilla”, Manuscrits. Revista d'història moderna, 10 (1992), pp. 61-76.

9 Ese origen más modesto fue puesto de manifiesto por Manuel Núñez Mercado al declarar ante la Inquisición de Cuenca que su padre Francisco Estévez de Mercado había sido mercader de ganados. Proceso de fe de Manuel Núñez Mercado, 1652, Archivo Diocesano de Cuenca (ADC), Inquisición, leg. 486, exp. 6531, fols. 135r-137v. La figura de Manuel Núñez Mercado y su familia ya fueron objeto de primeras, aunque breves, introspecciones. Contreras Contreras, J.: "Criptojudaísmo en la España Moderna. Clientelismo y linaje", Áreas. Revista Internacional de Ciencias Sociales, 9 (1988), pp. 77-101. Huerga Criado, P.: "Entre Castilla y los Países Bajos. Lazos familiares y relaciones personales", en Contreras Contreras, J., García García, B. J., y Pulido Serrano, J. I. (eds.): Familia, religión y negocio: el sefardismo en las relaciones entre el mundo ibérico y los Países Bajos en la Edad Moderna, Madrid, Fundación Carlos de Amberes, 2002, pp. 39-63.

10 Sobre el sistema de ferias regionales de Extremadura, Melón JimÉnEZ, M. A.: "Datos para el estudio de las ferias y mercados de Extremadura en la Edad Moderna", Revista de Estudios Extremeños, vol. LXXII, 1 (2016), pp. 265-294.

11 Pleito de Francisco Rodríguez Penamacor con el fiscal, agente y procurador general del Reino, s. f., AHN, Inquisición, leg. 5009. Escritura de traslado de una libranza de Carlos Strata sobre la renta del papel, 16 de abril de 1638, AHN, Inquisición, leg. 5009. En 1640 Penamacor también contrataría junto con el doctor Andrés de Fonseca un asiento para la anticipación de 32.000 ducados de vellón sobre los millones repartidos al Reino de Toledo. Traslado de auto despachado por don Antonio de Contreras por un asiento de anticipación de 32.000 ducados, 5 de junio de 1640, AHN, Inquisición, leg. 3641. 
destacado sería desempeñado por un primo del anterior: Henrique Núñez (¿?-1647). Este último contrataría entre 1640 y 1647 diversos asientos con la Corona por una cuantía total aproximada de 1.334 .000 escudos $^{12}$. La mayoría de ellos con la finalidad de proveer de numerario al Ejército de Extremadura. La muerte de Henrique Núñez a principios de octubre de 1647 dejaría a sus sobrinos, los referidos hermanos Baltasar, Juan y Manuel, como herederos del negocio familiar.

La elección de una escala "micro" de análisis centrada en el examen y reconstrucción de la trayectoria financiera de la casa Núñez-Mercado resultará de gran utilidad con objeto de estudiar el papel de sus miembros como agentes privados al servicio de la Corona española. Sobre todo en relación a la observación de otros fenómenos sociales y económicos como, por ejemplo, el influjo de las relaciones personales entre hombres de negocios y ministros del rey, los distintos mecanismos en que se fundamentaban la financiación de asientos menores y el crédito de los asentistas, o las innovaciones financieras introducidas por la Corona tras la bancarrota de 1647. Todo ello en paralelo a la reconstrucción de las actividades económicas de una familia que, al igual que en el caso de otros negociantes de la "nación portuguesa", llegaría a vincular sus propios intereses con los de la Monarquía Hispánica a través de la contratación de asientos con la Real Hacienda.

En la línea de encomiables trabajos como los de López Belinchón o Carrasco Vázquez, se pretende rescatar del olvido a estos hombres de negocios judeoconversos portugueses para comprobar el destacado papel desempeñado por los mismos en la vida social y económica de la Corona de Castilla durante los siglos modernos ${ }^{13}$. Pero ese mismo propósito exige ir más allá de la mera consideración de los referidos negociantes como miembros de una minoría etno-religiosa para pasar a abordar las prácticas y estrategias desarrolladas por los mismos en cuanto que conformantes del estrato superior del grupo socio-profesional ligado al comercio y las finanzas: aquél constituido por los mercaderes de grueso trato, los arrendadores de rentas y los asentistas $^{14}$. Se seguirá así la estela de estudios generales como los de David Smith y Jorge Pedreira sobre las élites mercantiles y financieras en el Portugal de los siglos XVII y XVIII, pero también de análisis de caso como el de Gaetano Sabatini acerca de los Vaaz, un linaje de influyentes banqueros judeoconversos portugueses en el Nápoles español del XVII ${ }^{15}$.

Para la consecución de los objetivos referidos este trabajo ha recurrido a la consulta de un variado conjunto de fuentes primarias. Por una parte, a los contratos de asientos y rentas reales custodiados en las secciones de "Contadurías Generales" y "Contaduría Mayor de Cuentas" del Archivo General de Simancas (AGS). Por otra, a un rico conglomerado constituido por la documentación incautada por la In-

\footnotetext{
Secuestro de bienes de Manuel Núñez Mercado, 1652, AHN, Inquisición, leg. 1896, exp. 1, fols. 101r-108r. Nota 5.

14 A este respecto resultan de gran interés algunos de los trabajos de Juan Ignacio Pulido. Pulido Serrano, J. I.: "Procesos de integración y asimilación: el caso de los portugueses en España durante la Edad Moderna", en Crespo Solana, A. (ed.): Comunidades transnacionales. Colonias de mercaderes extranjeros en el Mundo Atlántico (1500-1830), Madrid, Doce Calles, 2010, pp. 189-208. Pulido Serrano, J. I.: "Plural Identities: the Portuguese New Christians", Jewish History, 25 (2011), pp. 129-151.

15 Smith, D. G.: The Mercantile Class of Portugal and Brazil in the Seventeenth Century: A Socio-economic Study of the Merchants of Lisbon and Bahia, 1620-1690, tesis doctoral inédita, The University of Texas at Austin, 1975. Pedreira, J. M.: Os homens de negôcio da praça de Lisboa de Pombal ao Vintismo (1755-1822). Diferenciacão, reprodução e identificação de um grupo social, tesis doctoral inédita, Universidade Nova de Lisboa, 1995. Sabatini, G.: "The Vaaz: the rise and fall of a family of Portuguese bankers in Spanish Naples", Journal of European Economic History, vol. 39, 3 (2010), pp. 627-659.
} 
quisición española a Manuel Núñez Mercado en 1652, conservada en los fondos de la sección de "Inquisición" del Archivo Histórico Nacional de Madrid (AHN). Entre los documentos secuestrados se encuentran buena parte de las cartas recibidas por Manuel y sus hermanos entre 1643 y 1651, así como sus letras, borradores de cuentas y escrituras notariales. Dentro de ese conjunto documental cabe destacar la correspondencia epistolar por la abundante información que proporciona acerca de las actividades económicas de los Núñez-Mercado. Las cartas constituyen una fuente primaria de gran utilidad al permitir analizar el funcionamiento de este tipo de negocios financieros desde el punto de vista de sus propios actores económicos ${ }^{16}$. El contraste de esa información con la contenida en los contratos firmados ante el Consejo de Hacienda permitirá conocer más de cerca los mecanismos sobre los que se sustentaba el crédito de estos asentistas portugueses. Una cuestión para la que también resultan de utilidad varias escrituras notariales conservadas en el Archivo Histórico de Protocolos de Madrid (AHPM).

\section{El acceso a las finanzas reales: Henrique Núñez, un homo novus portugués}

La entrada de los Núñez-Mercado en el estrecho círculo de asentistas de la Corona tendría lugar en el año 1640 cuando uno de los principales patriarcas de la familia, el referido Henrique Núñez, firmase su primer gran contrato de asiento. Frente al modus operandi predominante en el caso de otros asentistas, que solía consistir en la invitación por parte de los ministros del Consejo de Hacienda a presentar un pliego o propuesta de asiento, la introducción de Henrique Núñez en el ámbito de las finanzas reales parece haber sido resultado de un procedimiento hasta cierto punto extraordinario. Concretamente, de las negociaciones particulares sostenidas entre este hombre de negocios y don Gaspar de Bracamonte y Guzmán, conde de Peñaranda de Bracamonte y consejero real en el Consejo de Castilla ${ }^{17}$. Como a tal ministro real, la Comisión de Millones del Reino había encomendado a Peñaranda la administración, beneficio, cobranza y anticipación de los 189.750 ducados asignados en quiebras de millones a Salamanca y su provincia -que incluía a los distritos fiscales de Extremadura- del servicio de 9 millones de ducados otorgado por las Cortes de Castilla para los años comprendidos entre 1638 y 1641 . Y es que desde 1635 la Corona recurrió al envío de jueces comisionados a las provincias para acabar con el fraude fiscal cometido por las autoridades municipales en la recaudación del servicio de millones. Al

16 Lamikiz, X.: "Un «cuento ruidoso»: Confidencialidad, reputación y confianza en el comercio del siglo XVIII", Obradoiro de Historia Moderna, 16 (2007), pp. 113-142. Aslanian, S. D.: "«The Salt in a Merchant's Letter»: The Culture of Julfan Correspondence in the Indian Ocean and the Mediterranean", Journal of World History, vol. 19, 2 (2008), pp. 127-188. RibeIRo, A. S.: "Letras de câmbio e correspondência comercial como materiais da história. O acto de cooperar sob olhares distintos", CEM Cultura, Espaço \& Memória: Revista do CITCEM, 2 (2011), pp. 159-169.

17 El conde de Peñaranda comenzó su carrera política ligado a la facción cortesana del conde-duque de Olivares. Embajador plenipotenciario de Felipe IV para las conferencias de paz de Münster entre 1645 y 1648, al regresar a Madrid disfrutaría de una cada vez mayor influencia en los círculos cortesanos, siendo nombrado consejero en el Consejo de Estado (1648) así como presidente del Consejo de Órdenes (1651) y del de Indias (1653). En 1658 sería designado virrey del Reino de Nápoles. FAYARD, J.: Los miembros del Consejo de Castilla (1621-1746), Madrid, Siglo XXI, 1982, pp. 127-128. Sobre este destacado personaje político también puede verse el reciente trabajo de Alistair Malcolm respecto a los grupos de poder cortesano en la segunda mitad del reinado de Felipe IV. Malcolm, A.: Royal Favouritism and the Governing Elite of the Spanish Monarchy, 1640-1665, Oxford, Oxford University Press, 2017. 
igual que el propio conde de Peñaranda, dichos jueces eran por lo general miembros del Consejo de Castilla a los que se dotó de amplios poderes jurisdiccionales para efectuar tales comisiones ${ }^{18}$.

Dado que a principios de 1640 no se había puesto cobro de un solo real, el conde de Peñaranda llegó a un acuerdo con Henrique Núñez para que este último llevase a cabo una anticipación de 144.000 ducados en la Corte en el plazo de un año. Peñaranda y Núñez acordaron que los 189.750 ducados de quiebras de millones compondrían la consignación mediante la cual Núñez obtendría el reembolso del principal e intereses -al 12\%- del asiento. Una vez presentado el primer pliego del asiento ante el Consejo de Hacienda, Peñaranda refirió en una consulta la idoneidad del mismo defendiendo la buena reputación de Núñez con las siguientes palabras: "de cuya puntualidad y hacienda tengo muy buena relación". Finalmente, el asiento fue firmado el 21 de febrero de 1640 tras reducir algunas de las peticiones iniciales de Henrique Núñez ${ }^{19}$. Mediante este compromiso la Corona estaba delegando la cobranza de las quiebras de millones de Salamanca y su provincia en un particular a cambio de obtener rápidamente dinero de contado, aunque ello supusiese perder una parte importante de su cuantía total por el pago de intereses. Así se explica que Henrique Núñez figurase con posterioridad en diversas escrituras notariales como "juez por su Majestad" para la administración y cobranza de los referidos efectos por subdelegación del conde de Peñaranda ${ }^{20}$. Sin duda, este asiento es una muestra de las grandes necesidades de numerario de la Monarquía, que se incrementarían a lo largo de 1640 con la apertura de los dos frentes bélicos peninsulares de Cataluña y Portugal en los meses de junio y diciembre respectivamente ${ }^{21}$.

A causa de dichos problemas financieros no pocas familias de "nuevos portugueses", es decir, sin vínculos de parentesco con las grandes casas financieras originarias de Lisboa, conseguirían adentrarse en las finanzas reales a lo largo de la década de 1640. Nos estamos refiriendo a parentelas que, salvo notables excepciones como las de los Cortizos o los Téllez-Montesinos, desempeñarían un rol secundario mediante la contratación de asientos de menor cuantía. Por lo general para proveer y anticipar numerario dentro de la propia península ibérica. En un primer momento los beneficios derivados de la entrada en el negocio de los asientos eran evidentes para estas familias de menor estatus socioeconómico. Ante los riesgos cada vez mayores del comercio exterior, sobre todo desde el inicio de la guerra con Francia en 1635, los asientos con la Corona proporcionaban una fuente más segura de beneficios mediante reembolsos en forma de diversas exacciones fiscales y rentas reales. Por no hablar de los suculentos intereses anejos a dichos contratos crediticios. No obstante, estos asentistas de segunda fila solían recibir consignaciones sobre efectos de menor calidad que los destinados a los principales financieros reales.

18 CÁrceles de GeA, B.: "Del Juez de Comisión al Comisario Real (1632-1643): el fraude fiscal como agente del «gobierno económico»", Studia Historica. Historia Moderna, 13 (1995), pp. 155-176. Sobre los servicios de millones, véase Gelabert, J. E.: La bolsa del rey. Rey, reino y fisco en Castilla (1598-1648), Barcelona, Grijalvo, 1997; y ANDrés UCEndo, J. I.: La fiscalidad en Castilla en el siglo XVII: los servicios de millones, 1601-1700, Zarautz, Universidad del País Vasco, 1999.

19 Asiento tomado con Henrique Núñez para la anticipación de 144.000 ducados, 15 de febrero de 1640, Archivo General de Simancas (AGS), Contaduría Mayor de Cuentas (CMC), 3ª́poca, leg. 2732, exp. 20.

20 Escrituras y cuentas de Henrique Núñez, 1643-1646, AHN, Inquisición, leg. 1872, exp. 1.

21 Elliott, J. H.: El conde-duque de Olivares. El político en una época de decadencia, Madrid, Crítica, 2010, pp. 607-658. 
A su vez, los contratos con la Corona proveían de una mayor seguridad jurídica a los hombres de negocios mediante la concesión de los privilegios jurisdiccionales y socioeconómicos contenidos en el "fuero de asentistas". Lo mismo con respecto a la prerrogativa de disponer de un juez conservador para el asiento, un ministro real al que se concedía jurisdicción privativa para intervenir en todos los pleitos y causas, ya fueran civiles o criminales, del asentista durante el tiempo que transcurriese la provisión de numerario y la cobranza de sus consignaciones ${ }^{22}$. Aunque es preciso aclarar que el juez conservador no tenía por objeto atender en exclusiva a los derechos de los hombres de negocios, ya que su figura era más bien resultado de la creación de un marco jurídico-institucional intermedio entre los intereses privados de los hombres de negocios y la economía política de la propia Corona ${ }^{23}$. Por lo que respecta al asiento firmado por Henrique Núñez en febrero de 1640, dado que se trataba de una provisión extraordinaria sobre el servicio de millones no incluiría explícitamente la figura de un juez conservador, aunque sí señalaba en una de sus cláusulas la posibilidad de que el conde de Peñaranda pudiese subdelegar su comisión real y los poderes jurisdiccionales anejos a ella a una persona de su elección. Subdelegación efectuada a posteriori sobre el propio Núñez, como se ha hecho mención más arriba.

Junto con la referida jurisdicción privativa, no menos evidentes eran las recompensas sociales que hombres de negocios como Henrique Núñez esperaban conseguir mediante sus contratos con la Corona. Por ejemplo, en este primer asiento Núñez solicitó entre sus condiciones la obtención de licencia para emplear coche de dos mulas en la Corte, un privilegio simbólico que finalmente le fue concedido ${ }^{24}$. Por consiguiente, los beneficios económicos y jurisdiccionales iban unidos a privilegios sociales que permitían a los miembros de parentelas como la de los Núñez-Mercado sentar las bases de procesos de movilidad ascendente ${ }^{25}$.

El caso de Henrique Núñez sirve también para observar el destacado papel desempeñado por el establecimiento de estrechas relaciones de colaboración particular con ministros reales como el conde de Peñaranda. Nuestra hipótesis es que el basamento de las mismas sería el intercambio del capital económico de estos hombres de negocios por el capital social y político de los ministros reales. Aunque no hemos podido observar trazas de la relación entre Núñez y Peñaranda con anterioridad a 1640, sí sabemos que ambos mantuvieron una amplia correspondencia económica hasta el fallecimiento de Henrique Núñez en 1647. Diez años después y coincidiendo con el punto álgido de su carrera política el conde de Peñaranda -por entonces presidente del Consejo de Indias- sería interpelado por ministros del Consejo de Inquisición acerca de su antigua relación con Henrique Núñez, a resultas de la averiguación que estaban realizando respecto a los bienes secuestrados a su sobrino y heredero Manuel Núñez Mercado en 1652. Extraemos aquí este interesante fragmento de la respuesta enviada por el propio conde:

22 Sanz Ayán, C.: Los banqueros y la crisis de la Monarquía Hispánica de 1640, Madrid, Marcial Pons, 2013, pp. 288-291.

23 García Montón, A.: "Corona, hombres de negocios y jueces conservadores. Un acercamiento en escala transatlántica (s. XVII)", Revista de Historia Jerónimo Zurita, 90 (2015), pp. 75-112.

24 Sobre las licencias de coches, López Álvarez, A.: Poder, lujo y conflicto en la corte de los Austrias: coches, carrozas y sillas de mano, 1550-1700, Madrid, Ediciones Polifemo, 2007.

25 SÁnchez Durán, A.: "Los hombres de negocios portugueses: una élite profesional en la Castilla del siglo XVII. Posibilidades de movilidad social e intermediación", Tiempos Modernos. Revista de Historia Moderna, vol. 31 , 2 (2015), pp. 193-220. 
De lo que me acuerdo fixamente y es pura verdad es que Enrrique Núñez ofreció prestarme 12.000 ducados para la otra Jornada de Alemania por la buena amistad y correspondencia que tenía con él y haviéndome dado la letra para Amberes y dejado yo acá hechas consignaciones y libramientos a razón de los 12.000 ducados que me prometió ${ }^{26}$.

El conde estaba refiriéndose a la financiación de los gastos de su viaje a Münster en 1645, donde se encargaría de negociar la paz con las Provincias Unidas tras ser nombrado por Felipe IV embajador plenipotenciario de España. A principios de 1645 Henrique Núñez le giró a Amberes una letra de cambio de 12.000 escudos de oro -tasados en 126.350 reales de plata- sobre Adão Dias Solis, corresponsal local de algunas de las principales firmas portuguesas en Madrid ${ }^{27}$. A cambio de este empréstito particular, que incluía unos onerosos intereses del 42\%, Peñaranda concedió a Henrique Núñez diversas consignaciones en España sobre efectos reales que habían estado bajo su control como consejero de Castilla ${ }^{28}$. A resultas de su capital político como ministro y embajador de la Corona española, Peñaranda también ofrecería otro tipo de sustanciales servicios a Henrique Núñez. El caso más paradigmático lo representa una carta remitida por Peñaranda al asentista portugués en septiembre de 1646 en la que le proponía poner a su disposición su amplia red de agentes y contactos en las Provincias Unidas y las ciudades hanseáticas para facilitarte la venta de lana castellana en esos enclaves: "[...] hace mal, VM, de no avisarme, dónde envía sus lanas porque en todas partes tengo amigos tanto en Ámsterdam y demás puertos destas provinçias como en qualquiera de las ciudades Anseáticas"29.

Entre la documentación secuestrada por la Inquisición a Manuel Núñez Mercado se encuentran varias cuentas que permiten conocer otros servicios económicos realizados por su tío Henrique Núñez al conde de Peñaranda. Por una cuenta sin fecha, seguramente de mediados de la década de 1640, podemos comprobar los distintos empréstitos realizados por Henrique Núñez a favor del conde para distintos propósitos, los cuales sumaban un total de 144.812 reales. Entre los mismos cabe destacar 20.000 reales destinados a la obra de la capilla del convento de Carmelitas Descalzas fundado por el conde en la cabeza de su estado nobiliario, la villa de Peñaranda de Bracamonte. Asimismo, en esa cuenta se refiere que el conde era deudor de 52.258 reales por el principal e intereses -a 31\% - de 39.892 reales que Henrique Núñez le había prestado para una de las jornadas reales al frente de Cataluña. En el Cuadro I se pueden observar las distintas partidas prestadas al conde, así como las consignaciones otorgadas por este último a modo de reembolso del numerario obtenido de Henrique Núñez.

26 Billete del Conde de Peñaranda (Madrid) a don Antonio de Estrada (Madrid), 18 de junio de 1657, Secuestro de bienes de Manuel Núñez Mercado, 1652, AHN, Inquisición, leg. 1896, exp. 1.

27 Boyajian, op. cit. (nota 4), pp. 152-153.

28 Papel del Conde de Peñaranda, 25 de febrero de 1645, Secuestro de bienes de Manuel Núñez Mercado, 1652 , AHN, Inquisición, leg. 1896, exp. 1.

29 Carta del Conde de Peñaranda (Münster) a Henrique Núñez (Llerena), 4 de septiembre de 1646, AHN, Inquisición, leg. 3941. 


\begin{tabular}{|l|r|}
\hline \multicolumn{1}{|c|}{ Libranzas de Henrique Núñez a favor del conde de Peñaranda } & Cuantía \\
\hline Librados para las obras de la capilla del convento de la villa de Peñaranda & 20.000 \\
\hline Librados para Alfonso Rodríguez Borges, asentista de su Majestad & 60.000 \\
\hline Letra de 39.892 reales a favor del conde (a 31\% de interés) & 52.258 \\
\hline Gasto de la casa del conde en Madrid TOTAL & 2.500 \\
\hline Librados al conde en otra partida TOTAL & 10.054 \\
\hline \multicolumn{2}{|c|}{ Cuantía } \\
\hline Consignaciones del conde de Peñaranda a favor de Henrique Núñez & 100.000 \\
\hline Escritura de obligación a favor de Henrique Núñez & 22.000 \\
\hline Libranza en la ciudad de Mérida & 1.940 \\
\hline Casa de aposento del conde & 20.872 \\
\hline Libranza en la administración del $4^{\circ}$ repartimiento en millones de Salamanca & 144.812 \\
\hline
\end{tabular}

Cuadro I. Cuenta entre Henrique Núñez y el conde de Peñaranda, s. f. [en reales de vellón]. Fuente: Cuenta de Henrique Núñez con el Conde de Peñaranda, s. f., Secuestro de bienes de Manuel Núñez Mercado, 1652, AHN, Inquisición, leg. 1896, exp. 1.

Este breve ejemplo resulta bastante ilustrativo tanto de las complejas interacciones económicas existentes entre hombres de negocios y ministros reales, como de la influencia que habrían desempeñado los últimos a la hora de posibilitar el acceso de nuevos financieros como Henrique Núñez al estrecho ámbito de los asentistas de su Majestad. Otra significativa prueba de lo referido puede constatarse a través de la documentación perteneciente al doctor Andrés de Fonseca, abogado y negociante portugués con estrechas relaciones con la familia Núñez-Mercado. Según una cuenta de 1642, el doctor Fonseca había prestado 157.166 reales de vellón y 22.800 reales de plata a don Luis Gudiel y Peralta, consejero en los Consejos de Cámara y de Castilla, para satisfacer sus deudas particulares y gastos de su casa durante una de sus comisiones para la cobranza de diversos efectos reales ${ }^{30}$. Un caso manifiesto de entrecruzamiento de los intereses públicos y privados dado que Gudiel era miembro de la Junta de prevención y monta de los criados de su Majestad con la cual el doctor Fonseca había firmado en 1642 un asiento de anticipación de 36.000 ducados de vellón. Gudiel también estaba al cargo de la cobranza de los efectos reales sobre los que se consignaron el principal e intereses de otro asiento de 32.000 ducados de vellón contratado por Fonseca en ese mismo año ${ }^{31}$.

Los casos hasta aquí citados no son sino una muestra de la cara oculta existente tras los contratos de asientos entre la Corona y estos agentes particulares, así como de la interconexión de las esferas pública y privada en la gestión de la Real Hacien-

30 Cuenta entre el doctor Andrés de Fonseca y don Luis Gudiel y Peralta, de los Consejos de Castilla y Cámara, s. f., AHN, Inquisición, leg. 4287, caja 2.

31 Asiento tomado con el doctor Andrés de Fonseca para la provisión de 36.000 ducados de vellón, 26 de marzo de 1642, AGS, Contadurías Generales (CCGG), leg. 136, caja 1. Subdelegación del señor don Luis Gudiel y Peralta al doctor Andrés de Fonseca, 14 de marzo de 1643, AHN, Inquisición, leg. 3764. 
$\mathrm{da}^{32}$. Por otra parte, los intercambios de prestaciones y servicios entre hombres de negocios y ministros reales constituyen una clara ilustración de la "economía de la merced" en la que se sustentaban las relaciones verticales de desigualdad que articulaban el sistema sociopolítico del Antiguo Régimen ${ }^{33}$.

\section{Asientos de provisión del Ejército de Extremadura (1641-1647)}

La más destacada implicación de Henrique Núñez en las finanzas de la Monarquía Hispánica tendría lugar en el periodo inmediatamente posterior a 1640, tras la sublevación de su nativo Reino de Portugal en diciembre de ese mismo año. La necesidad de acabar con la rebelión lusa encabezada por los partidarios del duque de Braganza, autoproclamado rey de Portugal como João IV, forzaría a Felipe IV y Olivares a crear un ejército real en la provincia fronteriza de Extremadura, por cuyas principales ciudades transitaba el camino real que comunicaba Madrid con Lisboa. Como consecuencia del costoso y peligroso frente abierto en Cataluña por los franceses aprovechando la rebelión del Principado en junio de 1640, el Ejército de Extremadura no pasaría de desempeñar una mera función defensiva al menos hasta finales de la década de $1650^{34}$. Aun así, el levantamiento de ese contingente militar y la manutención de sus soldados requeriría la movilización de los exiguos recursos fiscales de la Corona en los territorios limítrofes con Portugal. Es ahí donde Henrique Núñez y sus sobrinos desempeñarían un papel crucial ${ }^{35}$.

Al igual que la mayoría de miembros de las grandes casas de negocios portuguesas que desde 1626-1627 se habían establecido en Madrid para financiar a la Corona española, buena parte de los linajes de hombres de negocios de segunda fila decidieron mantenerse fieles a Felipe IV, entre ellos los Núñez-Mercado. Tras la rebelión de Portugal tratarían de mostrar su ejemplaridad como vasallos portugueses de la Corona frente al Tirano -sobrenombre por el que los "portugueses de Castilla" hacían mención al duque de Braganza-, vinculando su hacienda y crédito a la Casa de Austria. A resultas de ello entre 1640 y 1647 los Núñez-Mercado proporcionarían a la Real Hacienda cerca de 1.334 .000 escudos mediante distintos contratos de asiento. En este apartado analizaremos algunos de los principales asientos firmados por Henrique Núñez y sus sobrinos durante ese periodo para la provisión del Ejército de Extremadura. Concretamente hemos procedido a la selección de los tres asientos referidos en el Cuadro II, cuyas cuantías e intereses se indican a continuación:

32 Andújar Castillo, F.: “Cargos públicos y negocios privados en el tránsito del siglo XVII al XVIII”, Mélanges de la Casa de Velázquez. Nouvelle Série, vol. 46, 1 (2016), pp. 45-53.

33 Imízcoz Beunza, J. M.: "Las relaciones de patronazgo y clientelismo. Declinaciones de la desigualdad social", en Imízcoz Beunza, J.M. y Artola Renedo, A. (coords.): Patronazgo y clientelismo en la Monarquía Hispánica (siglos XVI-XIX), Bilbao, Universidad del País Vasco, 2016, pp. 19-41.

34 Valladares Ramírez, R.: Felipe IV y la restauración de Portugal, Málaga, Editorial Algazara, 1994. Para el Ejército de Extremadura, CoRTÉs CoRTÉs, F.: El Real Ejército de Extremadura en la Guerra de Restauración de Portugal (1640-1668), Cáceres, Universidad de Extremadura, 1985.

35 Sobre los asientos de provisión de ejércitos en la península ibérica, véase Rodríguez HernÁNDEz, A. J.: "Asientos y asentistas militares en el siglo XVII: el ejemplo del pan y la pólvora", Studia Historica: Historia Moderna, 35 (2013), pp. 61-98. 


\begin{tabular}{|c|c|c|c|c|}
\hline Asiento & Cuantía & \multicolumn{1}{c|}{ Intereses } & Consignación & \multicolumn{1}{|c|}{ Juez conservador } \\
\hline $\begin{array}{c}\text { Abril de } \\
1643\end{array}$ & 180.000 & $\begin{array}{l}8 \% \text { interés anual } \\
7 \% \text { conducción } \\
4 \% \text { adehala }\end{array}$ & 221.362 & \\
\hline $\begin{array}{c}\text { Enero } \\
\text { de } 1645\end{array}$ & 100.000 & $\begin{array}{l}8 \% \text { interés anual } \\
10 \% \text { conducción } \\
4 \% \text { adehala }\end{array}$ & 125.000 & $\begin{array}{l}\text { - Don Antonio de Valdés, consejero } \\
\text { de Hacienda. } \\
\text { - Don Juan de Santelices, consejero } \\
\text { de Hacienda }\end{array}$ \\
\hline $\begin{array}{c}\text { Mayo } \\
\text { de } 1645\end{array}$ & 177.000 & $\begin{array}{l}8 \% \text { interés anual } \\
8 \% \text { conducción } \\
4 \% \text { adehala }\end{array}$ & 221.513 & $\begin{array}{l}\text { - Don Diego Mexía de Guzmán, } \\
\text { marqués de Leganés, capitán } \\
\text { general del Ejército de Extremadura }\end{array}$ \\
\hline
\end{tabular}

Cuadro II. Asientos de provisión para el Ejército de Extremadura de 1643 y 1645 [en escudos

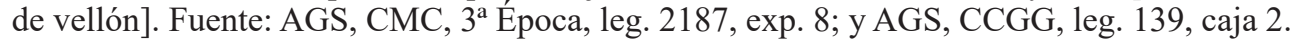

Las condiciones contratadas en estos asientos son bastante similares entre sí. En primer lugar, los pagos de las cuantías de los mismos (mesadas) debían realizarse en la ciudad de Badajoz, sede del cuartel general del Ejército de Extremadura. El asiento de abril de 1643 fue firmado por Henrique Núñez en solitario, aunque señalaba como partícipes en el mismo a su primo Jorge Núñez de Mercado y a Cristóbal Núñez, un destacado mercader de lanas por entonces residente en Sevilla. Henrique Núñez se comprometía a proveer 180.000 escudos de vellón a la pagaduría general del Ejército de Extremadura, encargada del pago de los salarios (soldadas) de sus efectivos. La provisión se realizaría en diez pagas de 18.000 escudos cada una ${ }^{36}$. En su asiento de enero de 1645 Henrique Núñez, de nuevo en solitario, se comprometió a proveer 100.000 escudos de vellón en diez pagas de 10.000 escudos cada una. Pero esta vez el dinero tendría por destino la proveeduría general del Ejército de Extremadura, responsable del abastecimiento del mismo. En concreto, el asiento establecía que el dinero sería empleado para la caballería de dicho contingente ${ }^{37}$. Por último, el asiento de mayo de 1645 sería contratado por Henrique Núñez junto con sus sobrinos Manuel Núñez Mercado, Juan Rodríguez Núñez y Baltasar Rodríguez Núñez. El contrato implicaba la provisión de 177.000 escudos de vellón a la pagaduría general del Ejército en un plazo más dilatado de 16 meses, a 11.062 escudos cada uno de ellos ${ }^{38}$.

Otra característica común a estos asientos de provisión fue el de realizarse en moneda de vellón. Es decir, estos contratos no implicaban pagos en el exterior como los grandes asientos de provisiones generales y a su vez tampoco requerían el empleo de moneda de plata. Un elemento común a buena parte de los asientos secundarios de provisiones y anticipaciones realizados en los dominios peninsulares de la Monarquía Hispánica. Por esa razón la Corona no habría de recurrir para la compensación de estos contratos a valiosas consignaciones como la plata proveniente de las Indias. Lo mismo con respecto a rentas reales como los almojarifazgos de Sevilla e Indias, o

36 Asiento tomado con Henrique Núñez para la provisión de 180.000 escudos de vellón, 16 de abril de 1643, AGS,

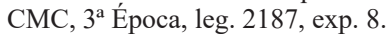

37 Asiento tomado con Henrique Núñez para la provisión de 100.000 escudos de vellón, 5 de enero de 1645, AGS, CCGG, leg. 139 , caja 2.

38 Asiento tomado con Henrique Núñez para la provisión de 177.000 escudos de vellón, 7 de mayo de 1645, AGS, CCGG, leg. 139, caja 2. 
los derechos de exportación de lanas, buena parte de cuyos ingresos eran en moneda de plata. De ahí que la mayor parte de las libranzas concedidas a Henrique Núñez como reembolso del principal e intereses de sus asientos se concedieran sobre rentas secundarias de los distritos fiscales de Salamanca y Extremadura, cobradas en exclusiva en moneda de vellón. Dado que el propio Núñez y parte de sus socios y corresponsales familiares residían en distintas localidades de Extremadura-Mérida, Badajoz, Llerena o Villanueva de la Serena-, eso garantizaba un rápido cobro del dinero desembolsado. Así ocurrió con la mayoría de las libranzas concedidas por su asiento de abril 1643, como se puede observar en el Cuadro III:

\begin{tabular}{|l|c|c|c|}
\hline \multicolumn{1}{|c|}{ Consignación } & Provincia & Cuantía & $\%$ \\
\hline $\begin{array}{l}\text { Situados de millones y sisas ordinarias de } \\
\text { Salamanca, Valencia de Alcántara, Cáceres, } \\
\text { Alcántara, Medellín, Feria, Plasencia, } \\
\text { Llerena, Trujillo }\end{array}$ & $\begin{array}{l}\text { Salamanca y } \\
\text { Extremadura }\end{array}$ & 18.295 .000 & 25,13 \\
\hline $\begin{array}{l}\text { Media anata de juros en las alcabalas de } \\
\text { Cáceres, Llerena, Mérida y Trujillo }\end{array}$ & Extremadura & 17.722 .000 & 24,35 \\
\hline $\begin{array}{l}\text { Media anata de juros en las alcabalas de } \\
\text { Plasencia }\end{array}$ & Extremadura & 1.571 .000 & 2,15 \\
\hline $\begin{array}{l}\text { Media anata de juros en las rentas de puertos } \\
\text { secos y diezmos de la mar de Castilla }\end{array}$ & Corte & 26.414 .000 & 36,29 \\
\hline Media anata de juros en la renta de las lanas & Corte & 8.780 .000 & 12,06 \\
\hline \multicolumn{2}{|c|}{ TOTAL } & 72.773 .000 & 100 \\
\hline
\end{tabular}

Cuadro III. Consignaciones del asiento de abril de 1643 [en maravedíes de vellón]. Fuente:

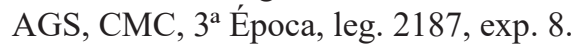

Como refleja el Cuadro III, un poco más de la mitad de las consignaciones serían cobradas en las provincias de Salamanca y Extremadura mientras que el cobro de la mitad restante se efectuaría en la Corte, lugar de residencia de Manuel Núñez Mercado. Por lo que respecta a los asientos de enero y mayo de 1645, en el primer caso se concedió una única libranza sobre la media anata de juros situados en las alcabalas de Sevilla y, en el segundo, se hizo lo propio con varias consignaciones sobre rentas situadas en la provincia de Extremadura "retrocedidas" -renunciadas en favor de la Corona- por varios asentistas de provisiones generales como los portugueses Jorge de Paz Silveira, Duarte Fernández de Acosta y Duarte Brandón Suárez, o el genovés Andrea Piquinotti.

Esas consignaciones en moneda de vellón constituirían el resorte fundamental de Henrique Núñez y sus socios. Por esa misma razón se podría afirmar que a priori no habrían sido tan dependientes del circuito de crédito atlántico, es decir, del eje Madrid-Sevilla-Amberes al que recurrían los principales asentistas de provisiones generales, especialmente las grandes casas de negocios portuguesas. Sin embargo, la compleja financiación de asientos menores como los contratados por Henrique Núñez requeriría también del acceso a la moneda de plata en que se sustentaba el referido circuito atlántico. 


\section{El caudal y crédito de los asientos: comercio interregional, exportación de lanas y letras}

Aunque las consignaciones en vellón fueran uno de los pilares del crédito de los Núñez-Mercado, la difícil cobranza de estas rentas por la excesiva presión fiscal a la que la Monarquía estaba sometiendo a sus dominios de la Corona de Castilla les supondría un grave problema. Por ejemplo, en junio de 1646 Henrique Núñez pedía a su sobrino Manuel Núñez Mercado que averiguase si era posible cobrar algunas cantidades en el partido de Salamanca por la pésima situación económica en que se encontraba por entonces la provincia de Extremadura: "conviene ver si se puede allá [Salamanca] cobrar que esta tierra está mui mala para cobrar" ${ }^{39}$. Dos meses después era Diego de Salvatierra y del Burgo, regidor de Salamanca y uno de los agentes de los Núñez-Mercado en esa ciudad, quien aconsejaba a Manuel Núñez que no tomasen más de 12.000.000 maravedíes en medias anatas de la provincia de Salamanca en el nuevo asiento que estaban negociando con el Consejo de Hacienda. Las razones de Diego de Salvatierra no podían ser más elocuentes al respecto:

[...] en quanto a las medias anatas de esta tesorería [Salamanca] lo que yo sé deçir a VMd que si por la Estremadura no se cobra alguna cossa no ay que azer casso, porque por acá todo es miseria y para azer buen asiento nunca VMd abía de tomar más que doze quentos en esta tesorería, aún estos no sé si los baldrán ${ }^{40}$.

La situación descrita por Diego de Salvatierra se tornaría peor en paralelo al deterioro de la situación financiera de la Real Hacienda, incapaz de hallar rentas con suficiente capacidad ("cabimiento") para sus asentistas. A finales de agosto de 1647, alrededor de un mes antes de su fallecimiento, Henrique Núñez se quejaba de los problemas que le estaba ocasionando un asiento de 120.000 escudos contratado meses atrás junto a sus sobrinos por la escasa calidad de las consignaciones otorgadas: "Este assiento de 120.000 diablos [escudos] nos a de hechar de el mundo ansí en el aprieto de las pagas dél, como en las cobranças pues ninguna a naçido" ${ }^{41}$. Por si fuera poco, la recaudación de los impuestos sobre los que descansaban sus consignaciones en Salamanca y Extremadura corría por mano de las autoridades locales, lo que originaba disputas y conflictos con las mismas. De ahí que en la propia Salamanca los Núñez-Mercado contasen como agentes de sus asientos con dos individuos ligados a la oligarquía municipal: el referido Diego de Salvatierra, regidor de la ciudad, y Baltasar de Benavente, tesorero de las alcabalas ${ }^{42}$. Lo mismo sucedería con respecto a otras ciudades como Segovia, donde confiarían la cobranza de diversas libranzas a don Pedro Meléndez Ayones, regidor perpetuo de la misma ${ }^{43}$. Una muestra de la

39 Carta de Henrique Núñez (Trujillo) a Manuel Núñez Mercado (Madrid), 4 de junio de 1646, AHN, Inquisición, leg. 3746, caja 2 .

40 Carta de Diego de Salvatierra y del Burgo (Salamanca) a Manuel Núñez Mercado (Madrid), 25 de agosto de 1646, AHN, Inquisición, leg. 3923.

41 Carta de Henrique Núñez (Llerena) a Manuel Núñez Mercado (Madrid), 30 de agosto de 1647, AHN, Inquisición, leg. 3944.

42 Véase por ejemplo el poder concedido en abril de 1649 por Manuel Núñez Mercado y sus hermanos a Diego de Salvatierra para cobrar 19.829.078 maravedíes en distintas libranzas que les habían sido concedidas sobre las alcabalas, millones y quiebras de millones del partido de Salamanca. Poder de Manuel Núñez Mercado a Diego de Salvatierra y del Burgo, 21 de abril de 1649, AHN, Inquisición, leg. 3956.

43 En abril de 1648 Manuel Núñez Mercado le otorgó poder para cobrar 11.989.750 maravedíes consignados sobre 
importancia de las relaciones con las élites locales de cara a garantizar la cobranza exitosa de las libranzas.

Sin embargo, ello no podía suplir la escasa calidad de determinados impuestos o su limitado "cabimiento", provocando graves atrasos que ponían en peligro el crédito de los asentistas. Por esa razón tenían que sustentar sus asientos en fuentes alternativas de financiación, como se ha podido comprobar en el caso de las grandes casas de asentistas genoveses y portugueses establecidos en Madrid. En el primer caso mediante el crédito obtenido en las principales ferias de cambio europeas, como Piacenza, Milán, Besançon o Lyon, y en el segundo a través del comercio en el ámbito atlántico, conectando los mercados del norte de Europa con las coronas ibéricas y sus dominios ultramarinos ${ }^{44}$. Por lo que se refiere a los asientos de provisión de Henrique Núñez y consortes, esas fuentes alternativas fueron tres principalmente: el comercio interregional en Castilla, la exportación de lanas finas al norte de Europa y el acceso a los circuitos de crédito peninsulares.

El comercio entre distintas regiones de la Corona de Castilla era un campo en el que los portugueses emigrados desde el interior de Portugal se mostraron muy hábiles ya desde los primeros compases del siglo XVII ${ }^{45}$. Frente a un tráfico indiano copado por los mercaderes del Consulado de Sevilla o por grandes firmas portuguesas como los Pasariño, Gramajo, Rodríguez Bueno, Solís o Suárez Dorta, numerosas familias de cristianos nuevos portugueses de menor hacienda y crédito se especializarían en el comercio interregional. Es el caso de las distintas ramas del clan Núñez-Mercado, que lograron conectar las ferias regionales de Extremadura con grandes centros de consumo y redistribución de mercancías como Madrid, así como con puertos como el de Málaga, punto clave del comercio internacional entre el Atlántico y el Mediterráneo ${ }^{46}$. Ya en su primer asiento con la Real Hacienda -la anticipación de 144.000 ducados-, Henrique Núñez se asociaría a sus sobrinos Juan y Baltasar Rodríguez Núñez para la adquisición de mercancías en Madrid y Málaga. Para ello los últimos contarían con la colaboración de sus tíos Francisco y Manuel Rodríguez Penamacor. El primero, a la par que tesorero general de la renta del azúcar y del impuesto del papel, les suministraba tejidos segovianos o franceses desde Madrid. El segundo actuaba como su agente comisionado en Málaga, remitiéndoles tejidos ingleses y flamencos adquiridos in situ.

las quiebras de millones de Segovia y su provincia. Poder de Manuel Núñez Mercado a don Pedro Meléndez Ayones, 11 de abril de 1648, Archivo Histórico de Protocolos de Madrid (AHPM), Protocolo 8347, Bartolomé Álvarez, fol. 236v.

44 Para la conexión genovesa con las grandes ferias de cambio, véase MArsilio, C.: «O dinheiro morreu. Paz à sua alma danada». Gli operatori finanziari del XVII secolo tra investimenti e speculazioni, Palermo, Associazione Mediterranea, 2012. En relación al vínculo de los financieros portugueses con el eje Atlántico, BoyAJIAN, op. cit. (nota 4), pp. 1-16. A pesar de lo que tradicionalmente se ha venido argumentando, los hombres de negocios genoveses no estuvieron completamente alienados del eje atlántico durante el siglo XVII. Así lo ha probado Alejandro García Montón a través del caso de estudio de Domingo Grillo. García Montón, A.: Génova y el Atlántico (c.1650-1680): emprendedores mediterráneos frente al auge del capitalismo del norte, tesis doctoral inédita, European University Institute, 2014. Lo mismo ha podido observarse con respecto a los cristianos nuevos portugueses residentes en Venecia. RusPIo, F.: La nazione portoghese. Ebrei ponentini e nuovi cristiani a Venezia, Turín, Silvio Zamorani Editore, 2007.

45 López Belinchón, op. cit. (nota 5), pp. 111-124.

46 Esa función sería reforzada desde mediados del XVII al convertirse Málaga en una importante avanzadilla económica para los mercaderes ingleses interesados en la comercialización de productos de la España meridional, como el vino o la pasa. MARTínez RuIZ, J. I.: " "A towne famous for its plenty of raisins and wines». Málaga en el comercio anglo-español en el siglo XVII”, Hispania. Revista Española de Historia, vol. LXXI, 239 (2011), pp. 665-690. 
En abril de 1641 Manuel Rodríguez Penamacor notificaba a su hermano Francisco que se hallaba "comprando las haziendas para embiar a los sobrinos a Medellín", sede de una de las principales ferias extremeñas ${ }^{47}$. Un mes después Juan Rodríguez refería haber recibido mercancías por valor de 9.743 reales desde Madrid y 43.945 reales desde Málaga $^{48}$. En julio de 1641 era su hermano Baltasar quien solicitaba crédito mediante letras a Francisco Rodríguez Penamacor por valor de hasta 40.000 reales para adquirir mercancías en Sevilla y Málaga, ofreciéndole reembolsos en las ferias extremeñas de Guadalupe, Zafra y Mérida donde llevaban a efecto la venta de esos productos ${ }^{49}$. Años después contarían con la participación de otros parientes como Antonio Ribero de Paiva, que en agosto de 1646 señalaba haber adquirido 3.000 ducados de mercancías en Málaga para remitir a sus primos Juan y Baltasar Rodríguez Núñez a la feria de Guadalupe ${ }^{50}$. La venta de tejidos en las ferias de Extremadura proveía a los Núñez-Mercado de una importante fuente de ingresos en moneda de vellón con la que hacer frente a las obligaciones de sus asientos y sostener su crédito en dicha provincia, basado en letras giradas sobre Sevilla y Madrid.

Aunque los contratos firmados por Henrique Núñez y sus sobrinos para la provisión del Ejército de Extremadura estipulaban que los pagos habían de realizarse exclusivamente en vellón, las constantes depreciaciones sufridas por esta moneda frente a la de plata imponían la necesidad de obtener numerario y crédito en plata para sostener la pesada carga de la financiación de los asientos ${ }^{51}$. Durante el siglo XVII la participación en el comercio internacional fue sin duda uno de los más recurridos mecanismos de acceso a la plata. Tanto el tráfico europeo como el indiano podían reportar amplios beneficios en dicho numerario. En el caso de los mercaderes residentes en España, una de las principales vías para obtener plata fue la exportación de la preciada lana castellana a los grandes núcleos de demanda de esta mercancía en Europa: Amberes, Ámsterdam, Hamburgo, Venecia o Livorno. El gran potencial del comercio de la lana residía en el hecho de poder ser adquirida en moneda de vellón en las principales zonas productoras de la península ibérica, como por ejemplo Burgos, Segovia, Soria, Extremadura o Aragón, para ser posteriormente vendida en moneda de plata en los citados mercados europeos. De ese modo, los márgenes de beneficios eran claramente superiores al añadir el plus del cambio de la plata al vellón, que durante la década de 1640 solía rondar un interés ("premio") medio cercano al $40 \% \%^{52}$. Eso explicaría el atractivo ejercido por la exportación de lanas para los comerciantes portugueses de menor caudal. De ahí que durante las primeras décadas del siglo XVII numerosos mercaderes portugueses fueran haciéndose con

47 Carta de Manuel Rodríguez Penamacor (Málaga) a Francisco Rodríguez Penamacor (Madrid), 9 de abril de 1641, AHN, Inquisición, leg. 3839, caja 1.

48 Carta de Juan Rodríguez Núñez (Mérida) a Francisco Rodríguez Penamacor (Madrid), 9 de mayo de 1641, AHN, Inquisición, leg. 3839, caja 1.

49 Carta de Baltasar Rodríguez Núñez (Mérida) a Francisco Rodríguez Penamacor (Madrid), 11 de julio de 1641 , AHN, Inquisición, leg. 3839, caja 1.

50 Carta de Antonio Ribero de Paiva (Málaga) a Manuel Núñez Mercado (Madrid), 21 de agosto de 1646, AHN, Inquisición, leg. 3923.

51 Para las persistentes alteraciones sufridas por la moneda de vellón, véase GARCía GuerRA, E. M.: "La moneda de vellón: un instrumento al servicio de la fiscalidad del Estado Moderno: las Cortes", Cuadernos de Historia Moderna, vol. 21 (1998), pp. 59-101. Serrano Mangas, F.: Vellón y metales preciosos en la Corte del Rey de España (1618-1668), Madrid, Banco de España, 1996.

52 En 1642 el premio sobre la plata llegaría a alcanzar una increíble media anual de $124,87 \%$ en el mercado madrileño. Ibidem, p. 78. 
una gran porción del mercado lanero en regiones como las comarcas sorianas ${ }^{53}$. Lo mismo ocurriría en otras áreas productoras de lana como Extremadura ${ }^{54}$. Además, la irrupción de los portugueses en el mercado lanero coincidiría con una recuperación de las exportaciones de lana castellana hacia Europa desde $1630^{55}$.

La importancia desempeñada por la lana como medio de obtención de financiación de los asientos puede ser observada en varios ejemplos extraídos de la documentación de los Núñez-Mercado. En octubre de 1645 Henrique Núñez ordenaba a su sobrino Manuel Núñez Mercado que se encargase desde Madrid de la adquisición de "una buena partida de lanas de Segovia", nada menos que 12.000 arrobas en total, para exportar a lo largo del año siguiente ${ }^{56}$. No sería el único mercado donde Henrique Núñez se abastecería de lana castellana, pues al año siguiente adquiriría toda la lana de la cabaña ovina del Monasterio de Guadalupe en Extremadura ${ }^{57}$. Una memoria remitida por Henrique Núñez en el referido mes de octubre de 1645 arroja pistas sobre el destino final de esa gran partida de lanas ${ }^{58}$. Esa memoria refleja no sólo los pasos que habría de seguir Manuel Núñez Mercado, sino también la complejidad de una operación mercantil que tenía por objeto la remisión de la lana hasta Ámsterdam. Es decir, el principal centro económico y financiero de uno de los hasta entonces más fieros enemigos de la Monarquía Hispánica: las Provincias Unidas.

Bajo responsabilidad de Manuel Núñez quedaría la remisión de las lanas adquiridas en Segovia hasta el puerto de Santander, donde don Fernando Antonio de Herrera Calderón, regidor perpetuo de la ciudad y agente local de los Núñez-Mercado, se encargaría de embarcarlas y de pagar los derechos de la renta de las lanas y de los diezmos de la mar de Castilla ${ }^{59}$. A su vez, Manuel debía contactar a través de Hamburgo con su pariente Jorge Núñez - también conocido por su nombre judío de Jacob de Mercado-, receptor final de la lana en Ámsterdam y encargado de la remisión de navíos neutrales hasta Santander ${ }^{60}$. Para que esta operación mercantil de cuasi contrabando tuviese éxito era preciso contar con la colaboración de terceras partes.

53 Diago Hernando, M.: "La irrupción de los conversos portugueses en el comercio de exportación de lanas de la Corona de Castilla en el tránsito del siglo XVI al XVII", Sefarad. Revista de estudios hebraicos y sefardies, vol. 70, 2 (2010), pp. 399-434.

54 Entre 1636 y 1646 todos los compradores de las lanas del Monasterio de Guadalupe en Extremadura fueron portugueses. Llopis Agelán, E.: "La pila de lana de la cabaña trashumante del monasterio de Guadalupe: dimensión, venta y estrategia comercial”, en GonzÁlez Enciso, A. (ed.): El negocio de la lana en España (1650-1830), Pamplona, Universidad de Navarra, 2001, pp. 29-76.

55 Un repunte que no se vería afectado por el inicio de la guerra con Francia en 1635. Desde 1627 diversos hombres de negocios portugueses como García de Illán, Manuel Cortizos y Simón de Fonseca Piña se sucedieron como arrendatarios de los derechos de las lanas de Castilla. IsRAEL, J. I.: "Spanish Wool Exports and the European Economy, 1610-40", The Economic History Review, New Series, vol. 33, 2 (1980), pp. 193-211.

56 Carta de Henrique Núñez (Badajoz) a Manuel Núñez Mercado (Madrid), 18 de octubre de 1645, AHN, Inquisición, leg. 3968.

57 Un total de 1.646 arrobas de lana. Llopis AgELÁN, op. cit. (nota 54), pp. 66 y 72.

58 Memoria de Henrique Núñez para el avío de las lanas, s. f., AHN, Inquisición, leg. 3968.

59 Otro de los puertos por donde los Núñez-Mercado exportaban lanas era San Sebastián, donde contaban con los servicios del encomendero vizcaíno Francisco de Beroiz Fagola. Carta de Francisco de Beroiz Fagola (San Sebastián) a Manuel Núñez Mercado (Madrid), 14 de octubre de 1646, AHN, Inquisición, leg. 3923. Durante la década de 1650 Francisco de Beroiz figuraría como uno de los principales intermediarios de diferentes mercaderes judíos portugueses de Ámsterdam vinculados al comercio con España. IsRAEL, J. I.: Empires and Entrepots. The Dutch, the Spanish Monarchy and the Jews, 1585-1713, Londres-Ronceverte, The Hambledon Press, 1990, pp. 410-415.

60 Uno de los navíos neutrales empleados en Santander sería "El Arado" del maestre Guillermo Brun. Carta de don Fernando Antonio de Herrera Calderón (Santander) a Manuel Núñez Mercado (Madrid), 14 de octubre de 1645 , AHN, Inquisición, leg. 3968. 
Así, las lanas se remitirían oficialmente hasta Hamburgo donde serían recibidas por un procurador local de Adão Dias Solis de Amberes. Para evitar cualquier problema con las autoridades de la Corona, en Santander habría de indicarse que las lanas eran remitidas por cuenta y riesgo del conde de Peñaranda para la financiación de los gastos de su embajada extraordinaria en Münster.

Desde una perspectiva social y política es preciso señalar la colaboración interesada de un influyente ministro real como el conde de Peñaranda, cuyos primeros gastos como embajador de la Corona española financió Henrique Núñez. La participación del conde en la operación era esencial para obviar el hecho de que el destinatario final de la lana fuese un mercader de la nación judía portuguesa de Ámsterdam, Jorge Núñez. Como se refiriera anteriormente, el propio Peñaranda ofrecería a Henrique Núñez en septiembre de 1646 sus contactos para vender partidas de lana en Ámsterdam y otras localizaciones de las Provincias Unidas. Una muestra de la porosa frontera existente entre los intereses privados del asentista y los intereses públicos de la Corona. Mediante la venta de lana en Ámsterdam Henrique Núñez obtendría un preciado capital con el que financiaría tanto el viaje del conde de Peñaranda a Münster, como el ejército real encargado de defender la frontera occidental de la Corona de Castilla frente al sublevado Portugal. Una representación del importante papel desempeñado por los asentistas portugueses en la Monarquía Hispánica, colaborando estrechamente con las autoridades políticas de la Corona como si de oficiales de la misma se tratasen. Algunos de ellos se convertirían en auténticos portfolio-capitalists al conseguir conectar las esferas mercantil-financiera y política tras su nombramiento como ministros u oficiales reales en distintos Consejos y Juntas de la Monarquía ${ }^{61}$. Ese sería el caso de asentistas como Francisco Díaz Méndez Brito, gran chanciller del Consejo de Cruzada, o Manuel Cortizos de Villasante, contador en la Contaduría Mayor del Consejo de Hacienda, secretario en la Junta de Millones y escribano mayor de las Cortes de Castilla ${ }^{62}$.

Es preciso añadir que tras la firma en 1648 de la Paz de Münster con las Provincias Unidas, los Núñez-Mercado podrían remitir directamente la lana a Ámsterdam sin recurrir a tales subterfugios. Así ocurrió a finales de 1649 con 80 sacones de lana segoviana exportados desde Santander en un buque fletado por Simón Méndez Soto, vecino de Ámsterdam ${ }^{63}$. Un borrador de cuentas de Manuel Núñez Mercado nos permite saber quiénes fueron los destinatarios de esa partida de lanas, así como el monto económico obtenido mediante su venta. Según dicho documento la lana fue vendida en Ámsterdam por Hendrique y Robert van de Star, pseudónimo empleado por los hermanos Fernando Álvarez y Antonio Correa de Amezquita en sus tratos con la península ibérica, reportando 4.873 ducados de plata para la casa Núñez-Mercado ${ }^{64}$.

El conde de Peñaranda no sería el único ministro real ligado de alguna manera a las transacciones laneras de los Núñez-Mercado. En junio de 1646 Henrique Núñez

${ }_{61}$ Con respecto al concepto de portfolio-capitalists, véase Subrahmanyam, S. y BaYly, C. A.: "Portfolio capitalists and the political economy of early modern India", The Indian Economic and Social History Review, vol. 25, 4 (1988), p. 401-424.

62 Proceso de fe de Francisco Díaz Méndez Brito, 1653-1655, AHN, Inquisición, leg. 142, exp. 6. SANZ AyáN, C.: "Procedimientos culturales y transculturales de integración en un clan financiero internacional: los Cortizos (siglos XVII y XVIII)", en Yun CASALILla, B. (ed.): Las redes del imperio. Élites sociales en la articulación de la Monarquía Hispánica, 1492-1714, Madrid, Marcial Pons, 2009, pp. 65-94.

63 Contreras Contreras, op. cit. (nota 9), p. 98.

${ }^{64}$ Cuaderno borrador de cuentas de Manuel Núñez Mercado, 1649-1652, AHN, Inquisición, leg. 1887, exp. 3, fol. $33 \mathrm{v}$. 
y Manuel Núñez Mercado dispusieron la compra en Segovia de buena parte de las 12.000 arrobas de lana referidas en octubre de $1645^{65}$. Entre los proveedores de dicha lana se encontraba don Antonio Mesía y Paz, caballero del hábito de Calatrava y administrador de los bienes de su hermano don Pedro Mesía de Tovar, conde de Molina de Herrera y consejero en el Consejo de Hacienda. Las relaciones económicas de los Núñez-Mercado con el conde de Molina de Herrera no se limitaban a la compra de lanas de su cabaña ovina. Como se puede observar en una escritura de obligación otorgada en septiembre de 1647 por don Antonio Mesía, Manuel Núñez Mercado se encargó de pagar por adelantado 60.000 reales que el conde de Molina debía por aquel entonces al mercader saboyano Bartolomé Arnolfo ${ }^{66}$. De ese modo, la concesión de crédito a los hermanos Mesía de Tovar habría constituido un tipo de servicio económico que Henrique Núñez y sus sobrinos verían ampliamente compensado gracias a la influencia política del conde de Molina en el seno del Consejo de Hacienda. Aunque se trata de un extremo para el que hasta el momento no hemos hallado pruebas documentales.

Por lo que respecta al mero punto de vista económico, la exportación de lanas a grandes mercados como Ámsterdam proveería a los Núñez-Mercado de ingresos y crédito en moneda de plata. Ese capital sería gestionado en forma de letras de cambio desde Amberes, el gran núcleo económico de los Países Bajos españoles estrechamente ligado a los dos principales centros financieros de la Corona de Castilla: Madrid y Sevilla. Precisamente sobre estas dos últimas ciudades se sostenía el crédito mediante letras de los Núñez-Mercado, otro de los mecanismos que esta familia portuguesa emplearía para financiar sus asientos. La letra de cambio era un instrumento financiero de primer orden que poseía una doble finalidad: realizar transacciones mercantiles en otros mercados y en diferentes monedas sin necesidad de recurrir a dinero de contado, así como obtener crédito de corresponsales financieros o de particulares ${ }^{67}$. Por consiguiente, la letra de cambio fue una herramienta básica del comercio internacional y el basamento de las redes crediticias de los principales banqueros genoveses y portugueses de la Monarquía Hispánica.

Menos atención se ha prestado al no menos importante papel desempeñado por la letra interior, conocida en Castilla simplemente como "letra" o "vale", en cuanto que resorte financiero de los contratos de asiento. Dado que buena parte de los pagos y la mayoría de las consignaciones de los asientos se realizaban dentro de la propia Corona de Castilla en su propia moneda, ya fuera en vellón o en plata, la letra era un mecanismo esencial para la circulación de crédito en el seno de su territorio. Del mismo modo que la letra de cambio, la letra era empleada como una herramienta que evitaba el traslado directo de numerario entre los mercados secundarios de Castilla y los principales centros financieros como Sevilla o Madrid ${ }^{68}$. Por esa razón, el mercado de letras fue un resorte fundamental de los asientos de provisión de numerario en los dominios peninsulares.

\footnotetext{
65 En esta operación se compraron 5.000 arrobas de lana a Francisco Frutos del Río y otras 1.500 arrobas a don Antonio de Mesía. Carta de Manuel de Valencia (Segovia) a Manuel Núñez Mercado (Madrid), 23 de junio de 1646, AHN, Inquisición, leg. 3746, caja 2.

66 Escritura de obligación de 60.000 reales a favor de Manuel Núñez Mercado, 29 de septiembre de 1647, AHPM, Protocolo 8346, Bartolomé Álvarez, fol. 479r. Sobre las interacciones económicas entre Arnolfo y el conde de Molina, véase Diago Hernando, M.: "Bartolomé Arnolfo, un saboyano en el Madrid del siglo XVII, financiero, mercader y señor de ganados trashumantes”, Studia Historica. Historia Moderna, 35 (2013), pp. 371-407.

67 De Roover, R.: L'évolution de la lettre de change (XIVe-XVIIIe siècles), París, Armand Colin, 1953.

68 Para el papel financiero de Madrid y Sevilla, véase BoYAJIAN, op. cit. (nota 4), pp. 60-69.
} 
Así se puede observar mediante el caso de los Núñez-Mercado. Su crédito giraba en torno a tres ejes fundamentales: Sevilla, Madrid y las ferias regionales de Extremadura. La provincia de Extremadura no sólo era el lugar de residencia de Henrique Núñez -quien fue vecino de Mérida y Llerena-, sino también donde habían de realizarse los pagos de los asientos del ejército real y la cobranza de parte de las consignaciones de los mismos. Desde Extremadura Henrique Núñez mantuvo una amplia circulación de crédito con respecto a Madrid, donde residía su sobrino y socio Manuel Núñez Mercado, y Sevilla, domicilio de sus agentes Diogo Rodrigues Luis y Simón Rodríguez Núñez, este último primo de Henrique Núñez. Precisamente, para analizar el peso de la financiación mediante letras utilizaremos el ejemplo de Sevilla mediante el examen de las cuentas de Diogo Rodrigues Luis con Manuel Núñez Mercado y sus hermanos ${ }^{69}$.

Esas cuentas, cerradas a finales de 1648, refieren todas las letras giradas desde Sevilla por Rodrigues Luis sobre Henrique Núñez y sus sobrinos. En especial son útiles para observar el crédito movilizado desde Sevilla entre octubre de 1645 y octubre de 1647, fecha esta última del fallecimiento de Henrique Núñez y de la suspensión de pagos decretada por Felipe IV. Asimismo, permiten conocer quiénes fueron los principales corresponsales financieros de los Núñez-Mercado tanto en Sevilla como en Madrid. Durante el referido periodo Diogo Rodrigues Luis obtuvo mediante las letras sacadas en Sevilla un total de 494.052 reales de plata y 2.011.948 reales de ve1lón. El sostén de este crédito no sólo procedería del estatus y reputación de Henrique Núñez como asentista de su Majestad, sino especialmente de algunas consignaciones concedidas a los Núñez-Mercado en Sevilla. Como por ejemplo una libranza de 125.000 escudos de vellón en la media anata de juros situados en las alcabalas de la ciudad de Sevilla como compensación por su asiento de enero de $1645^{70}$.

La importancia de esos circuitos de crédito mediante letras es puesta de manifiesto en una carta enviada por Henrique Núñez a Manuel Núñez Mercado en agosto de 1647. En la misma declaraba que, ante las dificultades para hacer frente a las pagas del último asiento contratado para la provisión de 120.000 escudos al Ejército de Extremadura, “es fuerça ymbiar a Sevilla por 200.000 reales". A los que se unirían los escasos 48.000 reales obtenidos por Henrique Núñez en Extremadura para pagar débitos de letras sacadas en Madrid ${ }^{71}$. Otro ejemplo del peso del crédito a través de letras en la financiación de estos asientos lo encontramos en los 60.000 ducados que Simón Rodríguez Núñez decía haber aceptado en letras giradas a Sevilla sobre él por Henrique Núñez y sus sobrinos hasta fines de septiembre de $1647^{72}$. El Cuadro IV refiere a los principales corresponsales financieros sobre los cuales Diogo Rodrigues Luis obtuvo crédito en plata entre 1645 y 1647 :

\footnotetext{
69 Cuentas de Juan Rodríguez Núñez, Manuel Núñez Mercado y Henrique Núñez con Diogo Rodrigues Luis, s. f., AHN, Inquisición, leg. 3949.

70 AGS, CCGG, leg. 139, caja 2.

71 Carta de Henrique Núñez (Llerena) a Manuel Núñez Mercado (Madrid), 30 de agosto de 1647, AHN, Inquisición, leg. 3944.

72 Carta de Simón Rodríguez Núñez (Sevilla) a Francisco Rodríguez Penamacor (Madrid), 15 de octubre de 1647, AHN, Inquisición, leg. 3944.
} 


\begin{tabular}{|l|c|c|}
\hline \multicolumn{1}{|c|}{ Corresponsal } & Nación & Cuantía \\
\hline Héctor de Olivares & Portugués & 71.088 \\
\hline Don Diego de Silveira & Portugués & 34.934 \\
\hline Don Diego Fernández Tinoco & Portugués & 32.492 \\
\hline Doña Violante Correa, viuda de Fernando Tinoco & Portuguesa & 22.770 \\
\hline Henrique Méndez de Quirós & Portugués & 20.930 \\
\hline Don Francisco de Silveira & Portugués & 16.942 \\
\hline Jorge Ribeiro Coaresma & Portugués & 16.400 \\
\hline Diego de Paiva & Portugués & 16.000 \\
\hline Domingo de Mendoza & Castellano & 14.767 \\
\hline Don Pedro Zoalli & ¿Genovés? & 13.500 \\
\hline Alejandro Palavesín & Genovés & 12.523 \\
\hline Carlos Coquel y Antonio Galle & Flamencos & 11.000 \\
\hline
\end{tabular}

Cuadro IV. Letras en plata sacadas en Sevilla por Diogo Rodrigues Luis (1645-1647) [en reales de plata]. Fuente: AHN, Inquisición, leg. 3949.

Como se puede observar, la mayoría de sus corresponsales en Sevilla fueron compatriotas portugueses, buena parte de ellos miembros de grandes casas financieras implicadas también en el negocio de la contratación de asientos. Ese fue el caso de Héctor de Olivares y Jorge Ribeiro Coaresma, hermano y tío respectivamente del asentista Duarte Díaz de Olivares ${ }^{73}$. Lo mismo puede decirse de doña Violante Correa y don Diego Fernández Tinoco, viuda e hijo respectivamente del asentista Fernando Tinoco, al que sucedieron tras su fallecimiento en $1644^{74}$. También destaca la presencia de don Diego y don Francisco de Silveira, sobrinos de Jorge de Paz Silveira, el principal asentista portugués de Felipe IV hasta $1647^{75}$. Mientras tanto, entre los no portugueses se cuentan el asentista genovés Alejandro Palavesín o los flamencos Carlos Coquel y Antonio Galle ${ }^{76}$. La implicación de todos ellos en los asientos de provisiones generales a Flandes, Italia o Alemania, pagados y reembolsados en moneda de plata, explica que figurasen entre los principales corresponsales en plata de los Núñez-Mercado.

La situación se mantiene bastante similar en cuanto a los corresponsales en moneda de vellón, como se aprecia en el Cuadro V. Se repiten nombres como el de Jorge Ribeiro Coaresma, sin duda el principal proveedor de crédito de los Núñez-Mercado. Junto a ellos aparecen otros portugueses también ligados a destacadas casas financieras como don Pedro Fernández Tinoco, hermano de don Diego Fernández Tinoco, o don Sebastián de Solís, hijo de Francisco Fernández de Solís, hombre de negocios fuertemente ligado al tráfico indiano. Además, cabe destacar que el tercer mayor aprovisionador en vellón sería el asentista genovés Andrea Piquinotti ${ }^{77}$.

Boyajian, J. C.: Portuguese Bankers and the International Payments Mechanism, 1626-1647, tesis doctoral, University of California-Berkeley, 1978, p. 37.

74 SAnZ Ayán, op. cit. (nota 22), pp. 254-258.

75 Ibidem, pp. 228-239.

76 Sobre Alejandro Palavesín. Ibidem, pp. 263-265. Álvarez NoGAL, op. cit. (nota 4), pp. 69-70.

77 Andrea Piquinotti sería uno de los principales financieros genoveses de la Monarquía Hispánica, sobre todo durante la década de 1650. Ibidem, pp. 75-79. 


\begin{tabular}{|l|c|c|}
\hline \multicolumn{1}{|c|}{ Corresponsal } & Nación & Cuantía \\
\hline Jorge Ribeiro Coaresma & Portugués & 109.522 \\
\hline Bernardo López Albín & Portugués & 63.839 \\
\hline Andrea Piquinotti & Genovés & 55.104 \\
\hline Don Sebastián de Solís & Portugués & 55.000 \\
\hline Don Luis Brandón & Portugués & 54.293 \\
\hline Don Pedro Fernández Tinoco & Portugués & 41.686 \\
\hline Don Francisco de Silveira & Portugués & 38.620 \\
\hline Gerónimo Núñez Chaves & Portugués & 38.200 \\
\hline Don Francisco Camelo Brandón & Portugués & 38.114 \\
\hline Antonio Núñez Marchena & Portugués & 37.585 \\
\hline Domingo de Mendoza & Castellano & 37.580 \\
\hline Diego de Paiva & Portugués & 35.600 \\
\hline
\end{tabular}

Cuadro V. Letras en vellón sacadas en Sevilla por Diogo Rodrigues Luis (1645-1647) [en reales de vellón]. Fuente: AHN, Inquisición, leg. 3949.

Que la mayoría de los individuos de quienes los Núñez-Mercado obtuvieran crédito fueran portugueses, por lo general también cristianos nuevos, no sería una mera coincidencia. Sin embargo, ello no debe llevar a pensar que estemos ante una suerte de solidaridad nacional o étnica. De hecho, la relación personal entre Henrique Núñez y algunos de los principales asentistas portugueses habría sido más bien escasa. A la distancia personal y económica que separaba a los grandes asentistas lisboetas de sus compatriotas implicados en asientos de provisiones menores se unía también un abismo social, puesto que clanes como los Paz-Tinoco o los Silveira disfrutaban de un estatus socioeconómico muy superior al de los Núñez-Mercado, anterior incluso a su establecimiento en Castilla durante las décadas de 1620 y $1630^{78}$. La mayor presencia de hombres de negocios portugueses entre los corresponsales crediticios de los Núñez-Mercado no podría ser entendida sin tener en cuenta su conexión con las redes de crédito atlánticas en que operaban. Esas redes tuvieron su origen en la diáspora de cristãos-novos portugueses hacia la Europa atlántica -Francia, Países Bajos españoles, Provincias Unidas, Inglaterra, Alemania (Hamburgo) - a lo largo de los siglos XVI y XVII. Un complejo fenómeno multicausal que les permitiría conectar las coronas de Castilla y Portugal, a la par que sus extensos dominios coloniales, con los principales mercados europeos ${ }^{79}$.

Por todo ello las cuentas de Diogo Rodrigues Luis con Henrique Núñez y sus sobrinos muestran la permeabilidad del crédito portugués durante el reinado de Felipe IV. Asentistas de segundo nivel como los Núñez-Mercado fueron también capaces de ligar los mercados del interior de la península ibérica con los grandes circuitos de crédito de la Europa atlántica. Desde el punto de vista comercial ha quedado de manifiesto su rol como intermediarios entre los mercados regionales de Castilla y los

78 Lo cual quedaría de manifiesto en la obtención por los primeros de distinciones sociales como hábitos de las órdenes militares portuguesas o castellanas. BoyAJIAN, op. cit. (nota 4), pp. 111-113.

79 Israel, J. I.: Diasporas within a Diaspora. Jews, Crypto-Jews and the World Maritime Empires (1540-1740), Leiden-Boston-Köln, Brill, 2002, pp. 1-39. Studnicki-Gizbert, D.: A Nation Upon the Ocean Sea. Portugal's Atlantic Diaspora and the Crisis of the Spanish Empire, 1492-1640, Nueva York, Oxford University Press, 2007, pp. 17-39 y 41-66. 
principales nodos del comercio internacional. Ya fuera adquiriendo tejidos ingleses y flamencos en Málaga para redistribuir en Extremadura, o exportando lana castellana a Hamburgo o Ảmsterdam. De modo que los mecanismos de financiación de los asientos del Ejército de Extremadura prueban la vinculación de estos contratos secundarios con una economía atlántica en la que los portugueses desarrollaron un rol crucial, especialmente durante la primera mitad del siglo XVII ${ }^{80}$.

\section{Quiebra y reconstrucción del crédito: la bancarrota de 1647 y sus consecuencias}

Octubre de 1647 sería un mes nefasto para la casa Núñez-Mercado tanto desde el punto de vista económico como personal. El primero de octubre Felipe IV decretó la suspensión de todas las consignaciones a sus asentistas, salvo algunas notables excepciones. Una quiebra técnica motivada por la incapacidad de la Real Hacienda para hacer frente a la gigantesca deuda contraída con sus banqueros, especialmente con los de la nación portuguesa. Unos pocos días después se produciría el fallecimiento de Henrique Núñez en la localidad extremeña de Llerena ${ }^{81}$. Su muerte no pudo ocurrir en un peor momento para los intereses financieros de la familia. Aunque en su testamento dejó por heredero universal a su sobrino Juan Rodríguez Núñez, asociado a sus hermanos Baltasar Rodríguez Núñez y Manuel Núñez Mercado, la suspensión del pago de consignaciones por parte de la Corona y el fallecimiento del cabeza de la casa de negocios provocarían la inmediata ruptura del crédito de los Núñez-Mercado. Una situación que se agravaría por el rechazo de la Corona a decretar una moratoria en el pago de deudas privadas a favor de los asentistas, ya que Felipe IV y sus ministros pretendían renegociar sus contratos con los mismos desde una posición de fuerza ${ }^{82}$.

Las primeras consecuencias se dejaron sentir en Sevilla sobre los factores del difunto Henrique Núñez. El 15 de octubre Simón Rodríguez Núñez refería a su primo Francisco Rodríguez Penamacor cómo se había visto obligado a buscar refugio en una iglesia ("acogerse a sagrado") para evitar ser detenido por mandato de sus acreedores, de los que había tomado prestados 60.000 ducados en letras para los asientos de Henrique Núñez y sus sobrinos. Situación similar vivió Diogo Rodrigues Luis, también forzado a ocultarse en un convento. Mientras tanto, diversos bienes de los Núñez-Mercado fueron embargados por orden de sus acreedores, como por ejemplo 174 sacas de lana con alrededor de 1.740 arrobas listas para embarcar en Sevilla ${ }^{83}$.

La situación era caótica entre los corresponsales y agentes de los Núñez-Mercado ante los rumores de una posible quiebra de la firma. Sobre todo por falta de noticias

${ }_{80}$ En ese sentido desempeñaron un papel similar al de casas genovesas como la de los Serra, que conectaron mercados secundarios como el del Reino de Nápoles con importantes nodos financieros como Piacenza, Génova o Madrid. Ben Yessef Garfia, Y.: "A Genoese merchant and banker in the Kingdom of Naples: Ottavio Serra and his business network in the Spanish polycentric system, c.1590-1620", European Review of History-Revue européenne d'histoire, vol. 23, 3 (2016), pp. 1-33.

81 Murió el día 6 de octubre. Carta de Simón Rodríguez Núñez (Sevilla) a Francisco Rodríguez Penamacor (Madrid), 15 de octubre de 1647, AHN, Inquisición, leg. 3944.

82 Sobre la quiebra de 1647 y sus consecuencias, BoyaJian, op. cit. (nota 4), pp. 154-180; SANZ Ayán, op. cit. (nota 22), pp. 177-207.

83 Carta de Simón Rodríguez Núñez (Sevilla) a Francisco Rodríguez Penamacor (Madrid), 15 de octubre de 1647 , AHN, Inquisición, leg. 3944. En Santander tenían otras 46 sacas de lana bajo poder de don Fernando Antonio de Herrera. Carta de don Fernando Antonio de Herrera Calderón (Santander) a Manuel Núñez Mercado (Madrid), 16 de noviembre de 1647, AHN, Inquisición, leg. 3945. 
de parte de los nuevos gestores de la casa. Así se explica el interés de algunos parientes por saber el estado en que se encontraba el negocio familiar, como se observa en una carta enviada desde Málaga por Baltasar Rodríguez Díaz a su tío Francisco Rodríguez Penamacor a finales de octubre: "Avíseme VMd el estado que mi primo Manuel Núñez Mercado tiene en essa Corte, que acá disen a quebrado" 84 . La situación a la que se enfrentaban los hermanos Juan Rodríguez, Baltasar Rodríguez y Manuel Núñez Mercado no podía ser más compleja. Por la bancarrota real se les suspendió el cobro en consignaciones de los 166.000.000 maravedíes -unos 488.235 escudos de vellón- que la Corona todavía debía a Henrique Núñez por los distintos asientos contratados desde $1640^{85}$. Unas consignaciones en las cuales los Núñez-Mercado habían sostenido buena parte de su crédito en forma de letras.

Ante esa difícil tesitura los hermanos Núñez-Mercado no tuvieron otra opción sino negociar un acuerdo con los ministros del Consejo de Hacienda. Esa tarea quedaría en manos de Juan Rodríguez Núñez y Manuel Núñez Mercado desde Madrid, mientras que Baltasar Rodríguez Núñez se ocuparía de atender el negocio familiar en Extremadura. Este último expuso a sus hermanos sus reticencias con respecto a la posibilidad de contratar un nuevo asiento para conseguir recuperar las deudas atrasadas por la Corona. Sus palabras reflejan además los problemas de crédito generados a resultas de la bancarrota, así como el daño generado en la reputación de esta casa de negocios:

yo ermano no quiero una vergüensa por quanto ay en el mundo, por amor de Dios que mires lo que azer en azientos que oy no nos está bien por muchas cauzas que sabes, lo uno que no ay crédito, lo otro [que] aunque aya mucho caudal nayde a de fiar ni querer meterse con nosotros visto lo $\operatorname{pasado}^{86}$.

Un claro ejemplo del estrecho lazo existente durante el Antiguo Régimen entre las nociones de crédito y reputación ${ }^{87}$. Estas últimas se situaban por encima de toda solidaridad nacional o étnica en cuanto que soportes de la confianza interpersonal, como queda de manifiesto en las palabras de Diogo Rodrigues Luis tras recibir la visita de varios acreedores portugueses al convento donde se hallaba refugiado:

Digo senhor que am benido los más de los acredores a este conbemto e com palavras no puedo emcaresser lo que pasó, siemdo que com ninguno se ha uzado lo que conmigo se ha uzado e com VMd, dizem que me aram todo el daño que pudierem e esto no som sino portugezes ${ }^{88}$.

\footnotetext{
84 Carta de Baltasar Rodríguez Díaz (Málaga) a Francisco Rodríguez Penamacor (Madrid), 28 de octubre de 1647, AHN, Inquisición, leg. 3926.

85 AHN, Inquisición, leg. 1896, exp. 1, fols. 101r-108r.

86 Carta de Baltasar Rodríguez Núñez (Mérida) a Juan Rodríguez Núñez y Manuel Núñez Mercado (Madrid), 2 de noviembre de 1647, AHN, Inquisición, leg. 3945.

87 Muldrew, C.: The Economy of Obligation. The Culture of Credit and Social Relations in Early Modern England, Londres, Palgrave, 1998, pp. 148-172. Vanneste, T.: Global Trade and Commercial Networks: EighteenthCentury Diamond Merchants, Londres-Nueva York, Routledge, 2011, pp. 91-95.

88 Carta de Diogo Rodrigues Luis (Sevilla) a Juan Rodríguez Núñez (Madrid), 19 de noviembre de 1647, AHN, Inquisición, leg. 3945.
} 
Finalmente, a mediados de noviembre de 1647 Juan y Manuel apostaron por desbloquear la situación presentando un pliego para contratar un nuevo asiento ${ }^{89}$. Las negociaciones con los ministros reales acerca de las condiciones finales se prolongarían hasta principios de marzo de 1648 , fecha de la firma del contrato definitivo ${ }^{90}$. Por el mismo los Núñez-Mercado se comprometían a suministrar 200.000 escudos de vellón en Sevilla para los presidios de España, cuyo abastecimiento corría a cargo de Octavio Centurión, marqués de Monesterio, por contrato de factoría ${ }^{91}$. Como condición sine qua non del asiento los hermanos Núñez-Mercado renunciaban a 40.000.000 de los 166.000.000 maravedíes que la Corona les debía en cuanto que herederos de Henrique Núñez. También aceptaron un interés fijo inferior, de un 5\% anual frente al $8 \%$ de anteriores asientos. A cambio de ello obtuvieron el compromiso de la Corona para que les fueran reembolsados los 126.000 .000 maravedíes restantes de la deuda. Mediante el nuevo asiento les fueron renovados los privilegios jurisdiccionales dimanados del "fuero de asentistas", así como la jurisdicción privativa mediante el nombramiento como su juez conservador del licenciado don Antonio de Valdés, consejero de los Consejos de Hacienda y de Castilla. Hecho bastante significativo con respecto al referido entrecruzamiento de intereses públicos y privados, puesto que don Antonio de Valdés era partícipe indirecto en los asientos de la casa Núñez-Mercado desde que en 1642 prestara 240.000 reales de vellón a Henrique Núñez, un capital que todavía figuraba en posesión de los sobrinos de Henrique Núñez a la altura de noviembre de $1647^{92}$. Por último, cabe señalar que mediante el nuevo asiento la Corona se les otorgó como merced la renovación de una licencia para portar coche de cuatro mulas concedida a Henrique Núñez en un asiento anterior.

$\mathrm{Al}$ margen de estas y otras condiciones la gran novedad de este contrato radicaba en los mecanismos de reembolso ofrecidos por la Real Hacienda. Unos cambios que iban a reforzar el vínculo de los Núñez-Mercado con los propios intereses económicos de la Monarquía. Junto a las tradicionales consignaciones sobre diversos efectos fiscales, la Corona introdujo un nuevo medio de pago que consistió en acordar con los Núñez-Mercado el arrendamiento de la renta de los azúcares del Reino de Granada, sobre cuyos ingresos cobrarían parte del numerario adeudado por la Corona ${ }^{93}$. Asimismo, como arrendadores de dicha renta estarían a cargo de pagar a otros factores y asentistas reales las consignaciones que se les hubieran concedido sobre la misma. Por tanto, se les otorgaba el papel de gestores del fisco regio a favor no sólo de sus propios intereses particulares, sino también de los de la propia Monarquía. Desde nuestro punto de vista se habría tratado de una suerte de reconocimiento - de facto que no de iure- de funciones hasta cierto punto similares a las de los factores

89 Carta de Simón Rodríguez Núñez (Sevilla) a Juan Rodríguez Núñez (Madrid), 26 de noviembre de 1647, AHN, Inquisición, leg. 3945.

90 Asiento tomado con Baltasar Rodríguez Núñez, Juan Rodríguez Núñez y Manuel Núñez Mercado para la provisión de 200.000 escudos de vellón, 5 de marzo de 1648, AGS, CCGG, leg. 142.

91 Sanz Ayán, C.: Un banquero en el siglo de oro. Octavio Centurión, el financiero de los Austrias, Madrid, La Esfera de los Libros, 2015, pp. 190-197.

92 Tras la detención de Manuel Núñez Mercado por el Santo Oficio en abril de 1652 todavía restaban por devolver a don Antonio 53.000 reales de la referida cuantía. Concurso de acreedores a los bienes de Manuel Núñez Mercado, 1654, AHN, Inquisición, leg. 4951, exp. 6, nº 24, fols. 1r-17v.

93 Mecanismo similar al introducido en el arrendamiento de rentas reales, para lo cual comenzó a exigirse a los hombres de negocios interesados en ellas la realización de asientos de anticipación en vez del tradicional abono de fianzas. López BeLInchón, op. cit. (nota 5), pp. 172-174. 
reales, aunque a una escala mucho menor y sin la obtención de los privilegios y responsabilidades ligados a los contratos de factoría, por lo general reservados por la Corona a los hombres de negocios de mayor caudal y crédito ${ }^{94}$.

El asiento estipulaba la concesión a los Núñez-Mercado del arriendo de la renta de los azúcares de Granada por un periodo de cinco años, comprometiéndose a recaudar un total de 140.000 .000 maravedíes, a razón de 28.000 .000 maravedíes anuales. En el Cuadro VI se pueden observar los beneficiarios de esa cuantía según los propios términos del asiento:

\begin{tabular}{|c|r|c|}
\hline Destinatario & \multicolumn{1}{c|}{ Cuantía } & $\mathbf{\%}$ \\
\hline Hermanos Núñez-Mercado & 78.200 .000 & 55,8 \\
\hline Factores y asentistas reales & 56.000 .000 & 40 \\
\hline Real Hacienda & 5.800 .000 & 4,15 \\
\hline TOTAL & 140.000 .000 & 100 \\
\hline
\end{tabular}

Cuadro VI. Destino de los ingresos de la renta de los azúcares de Granada (1648-1652) [en maravedíes de vellón]. Fuente: AGS, CCGG, leg. 142.

Alrededor de la mitad de la recaudación oficial de la renta del azúcar de Granada, 78.200.000 maravedíes, quedarían reservados para los Núñez-Mercado, que se obligaban a abonar 56.000.000 maravedíes a los factores y asentistas reales que tuvieran dicha renta por consignación de sus contratos. Otros 5.800.000 maravedíes irían destinados directamente a la Real Hacienda. Por tanto, un $40 \%$ de los ingresos de la renta tenían por objeto el pago del dinero adeudado por la Corona a algunos de sus más destacados financieros como el factor portugués don Felipe Denis Pacheco, o los factores genoveses don Jácome María Spínola, conde de Pezuela de las Torres, y Juan Esteban Imbrea, conde de Yebes ${ }^{95}$. Así, una parte destacable del reembolso de los contratos financieros con los citados factores dependería de la buena gestión de la renta de los azúcares por los hermanos Núñez-Mercado. De ahí se desprende que mediante su asiento de 1648 los Núñez-Mercado no sólo renovaban su papel de asentistas de provisiones de segundo nivel, sino que se convertían también en cierto modo en resortes del crédito de la propia Monarquía.

Desde el punto de vista del interés particular de los Núñez-Mercado, la combinación del contrato de asiento con el arrendamiento de una renta real era un mecanismo clave para la recuperación de su dañado crédito. La gestión de la renta les proporcionaba acceso directo a numerario con el que sostener de nuevo su crédito, superando así la desconfianza generada en otros particulares por las consecuencias de la bancarrota de octubre de 1647. Desde febrero de 1648, coincidiendo con las últimas fases de negociación del referido asiento, los Núñez-Mercado conseguirían restaurar su crédito en la Corte. Pero no sería en forma de letras sino de contratos notariales mediante los cuales obtuvieron dinero de contado de diversos particulares, con el

\footnotetext{
94 Respecto a los factores reales, SAnz Ayán, C.: Los banqueros de Carlos II, Valladolid, Universidad de Valladolid, 1988, pp. 34-40.

95 Carta de pago de Manuel Núñez Mercado sobre una libranza concedida a don Felipe Denis Pacheco, 15 de octubre de 1650, AHN, Inquisición, leg. 4029. Cesión de Manuel Núñez Mercado en favor del conde de Pezuela de las Torres, 23 de junio de 1649, AHN, Inquisición, leg. 4029.
} 
cual podrían ir haciendo frente tanto a las primeras pagas del nuevo asiento como a sus débitos ${ }^{96}$. En el Cuadro VII se refieren los préstamos contratados entre los meses de febrero y agosto de 1648 por Juan Rodríguez y Manuel Núñez ante Bartolomé Álvarez, escribano público de Madrid:

\begin{tabular}{|c|l|c|c|}
\hline Fecha & \multicolumn{1}{|c|}{ Prestamista } & Nación & $\begin{array}{c}\text { Cuantía } \\
\text { (*plata) }\end{array}$ \\
\hline $06 / 02$ & Don Jorge López Brandón & Portugués & 37.000 \\
\hline $11 / 02$ & Licenciado Juan Suárez de Acevedo & Portugués & 6.792 \\
\hline $19 / 02$ & $\begin{array}{l}\text { Doña Violante de Solís, viuda de Jorge Ribeiro } \\
\text { Coaresma }\end{array}$ & Portuguesa & 15.400 \\
\hline $27 / 02$ & Francisco Méndez de Castro & Portugués & 25.428 \\
\hline $28 / 02$ & Francisco Méndez de Castro & Portugués & 25.428 \\
\hline $10 / 03$ & Don Álvaro Fernández de Acosta & Portugués & 22.000 \\
\hline $10 / 03$ & Doña Violante Correa, viuda de Fernando Tinoco & Portuguesa & $44.296^{*}$ \\
\hline $10 / 03$ & Doña Violante Correa, viuda de Fernando Tinoco & Portuguesa & 26.268 \\
\hline $12 / 03$ & Santiago Munichicha & Vizcaíno & 11.000 \\
\hline $17 / 07$ & Don Francisco de Salazar y Haro & Castellano & 14.148 \\
\hline $18 / 08$ & $\begin{array}{l}\text { Don Francisco de Silveira y Manuel de Acosta } \\
\text { Sosa }\end{array}$ & Portugueses & $11.717 *$ \\
\hline
\end{tabular}

Cuadro VII. Escrituras de obligación de los Núñez-Mercado (febrero-agosto de 1648) [en reales de vellón]. Fuente: AHPM, Protocolo 8347, Bartolomé Álvarez.

Todos esos empréstitos suscritos ante escribano sentarían la base del renacer del crédito de esta familia portuguesa, favorecido sin duda por el reciente compromiso alcanzado con la Real Hacienda. No obstante, los distintos prestamistas harían incluir en sus contratos con los Núñez-Mercado una cláusula adicional según la cual estos últimos se obligaban a renunciar a los privilegios jurídicos derivados del fuero de asentistas, dado el amargo recuerdo de los impagos y quiebras de diversos hombres de negocios tras la bancarrota real de octubre de 1647.

Cabe señalar, además, que por el contrato de asiento de marzo de 1648 se les extendió el privilegio de juez conservador a la gestión de renta del azúcar de Granada, con lo que se incrementó la seguridad jurídica con la que podrían gestionar sus recursos. Los Núñez-Mercado tuvieron por juez privativo de la renta a don Juan González de Uzqueta, consejero en el Consejo de Indias e hijo del mismísimo presidente del Consejo de Hacienda, el influyente licenciado José González ${ }^{97}$. A pesar de ello, en julio de 1648 decidieron ahorrarse los cuantiosos gastos necesarios para poner cobro a la renta de los azúcares mediante su subarriendo a un consorcio portugués formado por Manuel Coptino Agramonte, Juan López Gómez y Fernando Gómez Díaz ${ }^{98}$.

96 Como por ejemplo los 42.250 reales de vellón que le estaban debiendo a don Leonardo de Fonseca Piña de resto de varias letras giradas a Sevilla sobre Simón Rodríguez Núñez. Escritura de obligación a favor de don Leonardo de Fonseca Piña, 14 de abril de 1648, AHPM, Protocolo 8347, Bartolomé Álvarez, fols. 238r-239r.

97 Sobre el licenciado José González, FAYARD, J.: “José González (1583?-1668) «créature» du comte-duc d’Olivares et conseiller de Philippe IV”, en Durand, Y. (ed.): Hommage à Roland Mousnier: clientèles et fidélités en Europe à l'époque moderne, París, Presses Universitaires de France, 1981, pp. 351-367. Sanz Ayán, op. cit. (nota 22), pp. 221-225.

98 AHN, Inquisición, leg. 1896, exp. 1, fols. 101r-108r. 
El mecanismo de la vinculación de un asiento con la gestión una renta real sería empleado de nuevo meses después. En concreto, con la firma del arriendo de la renta de la seda del Reino de Granada en diciembre de 1648 por un periodo de 10 años y unos ingresos totales fijados en 410.000 .000 maravedíes, a razón de 41.000 .000 maravedíes al año ${ }^{99}$. La Corona les renovó la jurisdicción privativa que ya gozaban para la renta del azúcar, de nuevo mediante la figura de don Juan González de Uzqueta como juez conservador ${ }^{100}$. Aunque la concesión de la renta a los hermanos NúñezMercado se realizó por medio de la vía tradicional de "remate" o subasta ante el Consejo de Hacienda, es bastante probable que la aceptación de su puja final se debiese al compromiso de la futura contratación de otro asiento con la Corona. De hecho, en el propio contrato de arrendamiento se refiere que el licenciado José González había propuesto a los Núñez-Mercado contratar un nuevo asiento de provisión, pudiendo renunciar al pago de los 20.000.000 maravedíes exigidos como fianza de la renta en caso de efectuarse dicho contrato.

Ese asiento vería la luz en febrero de 1649 con el compromiso de proveer 240.000 escudos de vellón en Badajoz para la pagaduría y proveeduría del Ejército de Extremadura. Para el reembolso del principal e intereses se les consignaron 97.752.000 maravedíes en distintos efectos reales, de los cuales 20.000.000 maravedíes fueron situados sobre la renta de la seda de Granada ${ }^{101}$. Por consiguiente, los hermanos Núñez-Mercado cobrarían esa última cantidad sobre unos efectos que ya gestionaban por sí mismos. Es probable que la Corona y los ministros del Consejo de Hacienda vieran en esta nueva política de vincular la contratación de asientos al arrendamiento de determinadas rentas reales un mecanismo para asegurar una mayor seguridad en el crédito de sus asentistas. En enero de 1649 y tras ponerse al frente de la renta de la seda como su tesorero general, un entusiasmado Baltasar Rodríguez Núñez indicaría a su hermano Juan que gracias a la renta podría proporcionarle hasta 120.000 ducados en letras giradas desde Granada hasta final de año. Si bien advirtiendo de la excesiva carga financiera que podría suponer para la casa de negocios el nuevo asiento para proveer al Ejército de Extremadura ${ }^{102}$.

\section{La Inquisición y el fin de una casa de negocios de la nación portuguesa}

Después de alcanzar su punto álgido entre 1648 y 1649, la participación de los Núñez-Mercado en la financiación de la Monarquía Hispánica finalizaría bruscamente en los años siguientes. El fallecimiento de Juan y Baltasar Rodríguez Núñez en julio de 1649 y marzo de 1650 , respectivamente, supondría un duro revés para la firma familiar. Desde ese momento Manuel Núñez Mercado asumiría la dirección de la casa de negocios en cuanto que heredero universal de sus dos hermanos, actuando como patrón de diversos primos que se situaron bajo su égida protectora: Baltasar

\footnotetext{
99 Asiento tomado por Juan Rodríguez Núñez y Baltasar Rodríguez Núñez para el arrendamiento de la renta de la seda del Reino de Granada, 31 de diciembre de 1648, AGS, CCGG, leg. 142.

100 Renovación de mandamiento de amparo de don Juan Gónzalez de Uzqueta a Manuel Núñez Mercado, 20 de diciembre de 1650, AHN, Inquisición, leg. 3962.

101 Asiento tomado con Baltasar Rodríguez Núñez, Juan Rodríguez Núñez y Manuel Núñez Mercado para la provisión de 240.000 escudos de vellón, 18 de febrero de 1649, AGS, CCGG, leg. 143, 18-2-1649.

102 Carta de Baltasar Rodríguez Núñez (Granada) a Juan Rodríguez Núñez (Madrid), 26 de enero de 1649, AHN, Inquisición, leg. 3951.
} 
Rodríguez Mercado (o Penamacor), Baltasar Rodríguez de Castro, Diego Rodríguez Mercado, Antonio Ribero de Paiva o Jorge Rodríguez de Castro.

La posterior ruina de la firma familiar no sobrevendría de problemas económicos, sino que tendría su origen en la detención de Manuel Núñez Mercado por la Inquisición en abril de 1652 bajo acusaciones de judaizante. Según las declaraciones de Manuel ante los inquisidores de Cuenca, por aquel entonces había cumplido ya con todas las provisiones de numerario comprometidas en sus asientos. Es más, precisó que la Real Hacienda le estaba debiendo 50.000 ducados en virtud de dichos contratos. También señalaría que pocos días antes de su apresamiento había alcanzado un compromiso con don Juan de Góngora, fiscal de la Comisión de Millones, para tomar de nuevo la renta del azúcar de Granada por siete años ${ }^{103}$. Tras permanecer en las cárceles secretas de la Inquisición de Cuenca hasta enero de 1656, un fallido intento de suicidio y el deterioro de su salud mental forzarían el ingreso de Manuel Núñez en el hospital general de Valencia. Allí fallecería el 7 de julio de ese mismo año sumido en un profundo estado de locura ${ }^{104}$. Su proceso quedaría así en suspenso sin que se pudiera demostrar su supuesta adhesión a la fe mosaica. Una rama secundaria de la familia encabezada por Jorge Núñez de Mercado -primo hermano de Henrique Núñez y partícipe en algunos de sus asientos- se mantendría al frente de la renta de la seda de Granada hasta 1654, año en que fue puesta en quiebra por el Consejo de Hacienda ${ }^{105}$.

La extinción de la casa de negocios de los Núñez-Mercado se produciría en paralelo a la de otras firmas portuguesas de ascendencia hebraica cuyos miembros serían víctimas de los masivos procesos de fe llevados a cabo por la Inquisición a lo largo de las décadas de 1650 y 1660 . Causas que llevarían al fin de casas de mediana negociación como las de los Chaves, Coello, Capadocia-Pato, Pimentel o Soria, y pondrían en serios apuros a poderosas firmas como las de los Téllez-Montesinos, Fonseca-Piña o Aguilar-Rendón. Incluso Francisco Díaz Méndez Brito, gran chanciller del Consejo de la Cruzada y cuñado del factor real don Felipe Denis Pacheco -cabeza de la poderosa casa Paz-Tinoco desde 1644-, llegaría a ser procesado por la Inquisición ${ }^{106}$. Por consiguiente, de cara al futuro será preciso explorar las motivaciones subyacentes tras esos procesos de fe atendiendo a explicaciones que vayan más allá de la meramente religiosa, es decir, la supuesta adherencia a prácticas criptojudías, dadas las graves consecuencias económicas y sociales derivadas de esas causas inquisitoriales. Entre ellas, la interrupción o completa paralización de los procesos de movilidad ascendente protagonizados por algunos de estos linajes de la nación portuguesa. Un caso bastante ejemplificador lo encontramos en la familia Vaaz de Nápoles, que gracias a sus actividades financieras pudo acceder a la nobleza titulada

103 AHN, Inquisición, leg. 1986, fols. 101r-108r.

104 ADC, Inquisición, leg. 486, exp. 6531, fols. 194r-197r.

105 La renta le fue traspasada por Manuel Núñez en noviembre de 1650 por los ocho años restantes de su arrendamiento y al mismo precio que fuera tomada por el propio Manuel y sus hermanos. Pleitos fiscales sobre los bienes secuestrados a Manuel Núñez Mercado, 1655, AHN, Inquisición, leg. 4952, exp. 7, no 2, fols. 7r9r. Acosado por sus deudas Jorge Núñez de Mercado huyó a Francia en 1658. Proceso de fe de Jorge Núñez de Mercado, 1667, ADC, Inquisición, leg. 533, exp. 6800. Respecto al parentesco de Jorge Núñez Mercado con Henrique Núñez, Avisos de Andrés de Belmonte al Consejo de Inquisición en orden a judaizantes, 14 de noviembre de 1661, AHN, Inquisición, libro 1131, fol. 334r-v. Jorge Núñez de Mercado es referido en diversas fuentes como "tío" de Manuel Núñez Mercado y sus hermanos, aunque es probable que se tratase de su tío segundo.

106 AHN, Inquisición, leg. 142, exp. 6. Sobre don Felipe Denis, SANZ Ayán, op. cit. (nota 22), pp. 283-284. 
de dicho reino a lo largo de la primera mitad del XVII. Sin embargo, la detención de los principales miembros de esta familia por la Inquisición napolitana en 1657, ligada a rivalidades políticas, destruiría las bases de un ascenso social cimentado a lo largo de tres generaciones ${ }^{107}$.

\section{Conclusiones}

Mediante el análisis "micro" proporcionado por el caso concreto de la trayectoria de una casa de negocios portuguesa de segunda fila ha sido posible constatar el destacado papel desempeñado por las mismas en la economía y finanzas de la Monarquía Hispánica, en especial durante un periodo crítico como fue el de la década de 1640. El estudio de los Núñez-Mercado contribuye a arrojar luz sobre factores hasta ahora bastante desconocidos como, por ejemplo, el proceso mediante el cual estas familias de menor caudal y crédito accedieron a la contratación de asientos con la Real Hacienda. Especialmente por lo que respecta a las estrechas relaciones económicas sostenidas con destacados ministros reales como el conde de Peñaranda de Bracamonte, cuyo examen ha permitido cotejar la existencia de una serie intercambios de servicios entre hombres de negocios y servidores de la Corona. Unas interacciones que muestran la fina línea que separaba los intereses privados de los anteriores respecto a los intereses públicos de la Real Hacienda. Se trata de una cuestión poco explorada a la que se será preciso dirigir una mayor atención en el futuro.

Por otra parte, los contratos de los Núñez-Mercado para la provisión del Ejército de Extremadura nos han permitido observar la capacidad de esta casa de negocios para movilizar crédito a partir de la obtención de consignaciones en vellón situadas sobre efectos y rentas cobraderos en los distritos fiscales de las provincias de Salamanca y Extremadura. En relación con ello han sido analizados los diversos mecanismos que sirvieron de soporte fundamental de la hacienda y crédito de esta casa de negocios, como el comercio interregional entre las ferias extremeñas y los principales mercados de la Corona de Castilla, o la exportación de lana fina castellana con destino a los Países Bajos españoles o las Provincias Unidas. Pero sobre todo se ha destacado el asiduo empleo a las letras interiores como instrumento fundamental para la obtención de crédito a partir de otros negociantes, portugueses o no, así como para la movilización de recursos monetarios entre distintos puntos de la geografía española. El uso de esas "letras" o "vales" resultó crucial para la financiación de los asientos efectuados en moneda de vellón en el seno del propio territorio peninsular, cuyo cumplimiento no requería del acceso forzoso a los circuitos de crédito atlántico, como en el caso de los asientos de provisiones generales a Flandes, Italia o Alemania.

El caso específico de los Núñez-Mercado también ha servido de faro de observación de las consecuencias dimanadas de la suspensión de pagos a asentistas decretada por Felipe IV en octubre de 1647. En especial, con respecto a la ruptura del crédito mediante letras en que se sostenía buena parte de la financiación de sus asientos, ya que el reembolso de dichas letras estaba ligado a las consignaciones otorgadas mediante dichos contratos. Del mismo modo, se ha podido comprobar cómo los Núñez-Mercado eludieron su quiebra mediante un acuerdo con la Real Hacienda que

107 SABATINI, op. cit. (nota 15), pp. 642-651. 
conllevó la renuncia a parte de los efectos adeudados por la Corona y la firma de un nuevo asiento. Lo más destacable de los asientos firmados en 1648 y 1649 por los Núñez-Mercado es que dichos contratos estuvieron directamente ligados al arrendamiento de rentas reales. En nuestra opinión se trató de una práctica favorecida por la Corona a partir de la bancarrota de 1647 con el fin de reducir parcialmente el riesgo asumido por los asentistas, que así podían controlar directamente la cobranza de los efectos fiscales sobre los que se consignaban parte del principal e intereses de sus contratos.

Por último, se ha abordado brevemente el final de la trayectoria de la casa NúñezMercado en el mundo de las finanzas como consecuencia del contexto de mayor represión inquisitorial contra los cristianos nuevos portugueses que dio comienzo en la década de 1650. Los Núñez-Mercado fueron uno más de los numerosos linajes de judeoconversos portugueses que a resultas de la acción inquisitorial vieron truncados procesos de movilidad ascendente cuyas primeras bases se habían fundado en el acceso a la contratación de asientos o el arrendamiento de rentas. De cara al futuro será preciso analizar si la desaparición de numerosas casas de negocios portuguesas habría favorecido la irrupción de una serie de financieros castellanos que comenzaron a desempeñar un creciente rol en las postrimerías del reinado de Felipe IV ${ }^{108}$.

108 De hecho, el desplome de las provisiones de plata por parte de los portugueses en 1653 sería suplido por hombres de negocios españoles. SANZ Ayán, op. cit. (nota 94), pp. 168-173. 